\title{
Fenton Reagent Reduces the Level of Arsenic in Paddy Rice Grain
}

\author{
Junhao Qin 1,2, Yongjun $\mathrm{Li}^{3}$, Minling Feng ${ }^{3}$, Huashou $\mathrm{Li}^{1 *}$ and Chuxia Lin ${ }^{2 *}$ \\ ${ }^{1}$ College of Natural Resources and Environment, South China Agricultural University, Guangzhou, \\ China
}

${ }^{2}$ School of Environment and Life Science, University of Salford, Greater Manchester M5 4WT United Kingdom

${ }^{3}$ Zhongshan Quality Supervision and Inspection Institute of Agricultural Products, Zhongshan, China

*Corresponding authors: $\underline{\text { C.Lin@ } @ \text { salford.ac.uk; lihuashou@scau.edu.cn }}$ 


\begin{abstract}
Hydroponic and pot experiments were conducted to examine the effects of Fenton reagent on paddy rice plant growing in arsenic-contaminated soils. Fenton reagent significantly reduced arsenic phytotoxicity, uptake by the plants and accumulation in rice grain. This is attributed to oxidation of $\mathrm{As}^{3+}$ to $\mathrm{As}^{5+}$ by hydroxyl radicals and immobilization of arsenate by reacting with precipitating $\mathrm{Fe}^{3+}$ to form practically insoluble compounds. Although this process enhanced the formation of Feenriched coatings on root surface, it appears that root plaque had limited effects on inhibiting As uptake since most of the young roots were not covered by iron plaque. It is more likely that As immobilization in the bulk soils play a major role in reducing As flux towards rhizosphere. The findings have implications for understanding As behavior in paddy field receiving rainwater-borne hydrogen peroxide and developing cost-effective techniques for reducing As level in rice grain produced from As-contaminated soils.
\end{abstract}

Keywords: Paddy rice, arsenic, iron plaque, soil, Fenton reaction 


\section{$1 \quad$ INTRODUCTION}

Consumption of rice is a major pathway of human arsenic exposure, which could affect billions of people around the world (Schoof et al., 1999; Meharg, 2004; Williams et al., 2006; Zhu et al., 2008; Syu et al., 2015; Sinha and Bhattacharyya, 2015; Clemens and Ma, 2016). The anaerobic soil conditions associated with water inundation required for paddy rice farming favour reduction reactions, leading to formation of highly toxic arsenite ions (Xu et al., 2008; Li et al., 2009; Somenahally et al., 2011; Spanu et al., 2012). Arsenite tends to be predominantly present in undissociated form $\left(\mathrm{H}_{3} \mathrm{AsO}_{3}{ }^{\circ}\right)$ under $\mathrm{pH}$ conditions encountered in most paddy rice soils (Zhao et al., 2009), and therefore it may be more resistant to immobilization by soil adsorbents. In addition, under reducing conditions the arsenic-scavenging capacity of soil is weakened due to reductive dissolution of various iron compounds that play a key role in binding soluble arsenic species through either formation of practically insoluble iron arsenate minerals or adsorption of arsenate to iron oxyhydroxides (Zhao et al., 2010; Zhu et al., 2014). As such, arsenite is readily available for uptake by rice plants and accumulation in rice grain (Williams et al., 2007; Su et al., 2010; Wang et al., 2015).

Iron-enriched root plaque plays an important role in reducing the entry of As present in the soil pore water (soil solution) into rice plant roots (Lee et al., 2013; Syu et al., 2013). The formation of root plaque is believed to be mediated by oxidation of ferrous iron $\left(\mathrm{Fe}^{2+}\right)$ using molecular oxygen released from rice plant roots (Armstrong, 1964), and it is likely that the root-released oxygen also promotes microbially mediated oxidation of arsenite to form arsenate (Hu et al., 2015). As arsenate has the stronger affinity to $\mathrm{Fe}^{3+}$, it is likely that arsenate-As tends to be intercepted more easily by the root plaque, as compared to arsenite-As (Chen et al., 2005; Liu et al., 2005).

It has been demonstrated that Fenton process involving reaction between hydrogen peroxide $\left(\mathrm{H}_{2} \mathrm{O}_{2}\right)$ and ferrous iron $\left(\mathrm{Fe}^{2+}\right)$ resulted in enhanced oxidation of arsenite to form less toxic arsenate 
(Hug and Leupin, 2003). $\mathrm{Fe}^{2+}$ is available in flooded soils like paddy rice soils (Becker and Asch, 2005; Kögel-Knabner et al., 2010). $\mathrm{H}_{2} \mathrm{O}_{2}$ is also commonly present in rainwater (Cooper et al., 1988; Willey et al., 1996; Gonçalves et al., 2010; Guo et al., 2014). In areas with abundant rainfall, Fenton reaction may be a naturally-occurring process that can affect the biogeochemical behaviour of arsenic in paddy rice soils. Where the enrichment of arsenic in rice grain becomes a significant health concern, it may be worthwhile to consider the use of Fenton reagent (a mixture of $\mathrm{H}_{2} \mathrm{O}_{2}$ and $\mathrm{Fe}^{2+}$ ) for reducing As uptake by rice plants.

The objective of this study was to examine the effects of Fenton reagent on reducing As uptake by rice plants. The impacts of Fenton reagent on plant growth are also evaluated. In addition, the major biogeochemical mechanisms responsible for the observed phenomena are explored.

\section{MATERIALS AND METHODS}

\subsection{Materials}

\subsubsection{Hydroponic Nutrient Solution}

The hydroponic nutrient solution used for the solution culture experiment consisted of the following chemical compounds: $5 \mathrm{mM} \mathrm{NH}_{4} \mathrm{NO}_{3}, 2 \mathrm{mM} \mathrm{K}_{2} \mathrm{SO}_{4}, 4 \mathrm{mM} \mathrm{CaCl} 2,1.5 \mathrm{mM} \mathrm{MgSO} 4 \cdot 7 \mathrm{H}_{2} \mathrm{O}$, $1.3 \mathrm{mM} \mathrm{KH}_{2} \mathrm{PO}_{4}, 50 \mu \mathrm{M} \mathrm{Fe}(\mathrm{II})$ )-ethylenediaminetetraacetic acid (EDTA), $10 \mu \mathrm{M} \mathrm{H}_{3} \mathrm{BO}_{4}, 1.0 \mu \mathrm{M}$ $\mathrm{ZnSO}_{4} \cdot 7 \mathrm{H}_{2} \mathrm{O}, 1.0 \mu \mathrm{M} \mathrm{CuSO} \cdot 5 \mathrm{H}_{2} \mathrm{O}, 5.0 \mu \mathrm{M} \mathrm{MnSO} \cdot \cdot \mathrm{H}_{2} \mathrm{O}, 0.5 \mu \mathrm{M} \mathrm{Na} \mathrm{MoO}_{4} \cdot 2 \mathrm{H}_{2} \mathrm{O}$, and $0.2 \mu \mathrm{M}$ $\mathrm{CoSO}_{4} \cdot 7 \mathrm{H}_{2} \mathrm{O}$. The $\mathrm{pH}$ of the solution was adjusted to 5.5 using $0.1 \mathrm{M} \mathrm{KOH}$ or $\mathrm{HCl}$.

\subsubsection{The Experimental Soil}

The soil sample used for the greenhouse experiment was taken from the paddy rice field of the experimental farm at the South China Agricultural University (Guangzhou, China). The soil samples were air-dried after collection and then crushed to pass a $2 \mathrm{~mm}$ sieve prior to the use in the 
experiments. The soil had a $\mathrm{pH}$ of 6.52 and contained $2.38 \%$ of organic matter. Total nitrogen, phosphorus and potassium were 1.06, 1.04 and $19.6 \mathrm{~g} / \mathrm{kg}$, respectively. Available nitrogen, phosphorus and potassium were 114, 77.8 and $122 \mathrm{mg} / \mathrm{kg}$, respectively. The soil contained 15.6 $\mathrm{mg} / \mathrm{kg}$ of arsenate-As and no other arsenic species were detected.

\subsubsection{The Rice Seedlings Used in the Experiment}

The seeds of rice (Oryza sativa cultivar: Tianyou 122) used in the experiment were provided by the Guangdong Academy of Agricultural Sciences. Prior to sowing, the seeds were surfacesterilized by soaking in $30 \% \mathrm{H}_{2} \mathrm{O}_{2}$ for $15 \mathrm{~min}$. The sterilized seeds were then rinsed with deionized water and placed in a container with moistened sands for germination. The pre-germinated seeds were sown into the seed bed that was covered by a plastic sheet to maintain the temperature at $28 \pm$ $2{ }^{\circ} \mathrm{C}$. Healthy seedlings with 4 leaves were selected for the experiment.

\subsection{Experimental Design}

\subsubsection{Solution Culture Experiment}

The rice seedlings were grown in the hydroponic nutrient solution for 3 weeks. The seedlings were then rinsed with deionized water and transplanted into a beaker containing $500 \mathrm{~mL}$ of $20 \mathrm{mg}$ $\mathrm{Fe}^{2+} / \mathrm{L}$ solution ( $\mathrm{pH}$ being adjusted to 5.5 ) for $24 \mathrm{~h}$ to allow the formation of iron plaques on the root surfaces of the seedlings. After this, the seedlings were rinsed to remove any soluble Fe attached to the plant surface before being used in the experiments.

Two sets of the experiments were performed aiming to collect data at the end of two different lengths of growth period: 1 day $(24 \mathrm{~h})$ and 30 days $(720 \mathrm{~h})$. For each set of the experiment, one control and one treatment were set; (a) control: plant growing in the hydroponic nutrient solution with added arsenite-As at a dose of $1 \mathrm{mg} / \mathrm{L}$; (c) Treatment: plant growing in the hydroponic nutrient 
solution with added arsenite-As at a dose of $1 \mathrm{mg} / \mathrm{L}$ plus Fenton reagent $\left(100 \mu \mathrm{M} \mathrm{H}_{2} \mathrm{O}_{2}\right.$ and $100 \mu \mathrm{M}$ $\mathrm{Fe}^{2+}$ ). For the 1-day experiment, the control and treatment were labelled as $\mathrm{C} 1 \mathrm{~d}$ and $\mathrm{T} 1 \mathrm{~d}$, respectively. For the 30-day experiment, the control and treatment were labelled as C30d and T30d, respectively.

A $500 \mathrm{~mL}$ plastic cup (diameter: $8 \mathrm{~cm}$; height: $15 \mathrm{~cm}$ ) was used as a hydroponic container, which was placed into a black nylon bag to avoid exposure of the plant roots to light. The lid with holes was used to support the plants. Six rice plants were grown in each hydroponic container. The plant growth units were placed randomly in a climate chamber with the daily light-dark cycle being set at $16 \mathrm{~h}: 8 \mathrm{~h}$. The light density during the photoperiod was fixed at $2500 \mathrm{~lx}$. Temperature during the dark and light periods was set at $20{ }^{\circ} \mathrm{C}$ and $28{ }^{\circ} \mathrm{C}$, respectively. Relative humidity was maintained at a range of 80-85\%. All the experiments were performed in 4 replicates.

For the 30-day experiment, the culture solution in each hydroponic container was replenished every 3 days. This included addition of arsenite-As for the control and addition of arsenite-As plus Fenton reagent for the treatment.

At the end of the 1-day experiment, samples of the spent culture solution were taken to determine various As species. For the 30-day experiment, only the first (3 days or 72 hours) spent culture solution was used for analysis of As species. These spent solution samples were labelled as CS1d and TS1d for the control and treatment of the 1-day experiment, respectively, and CS3d and TS3d for the control and the treatment of the first spent solution of the 30-day experiment, respectively.

At the end of each experiment, the plants were harvested for determinations of biomass, various As species in the plant tissues, and $\mathrm{Fe}$ and various As species in the root plaques. Since all the six plants growing in each hydroponic container had very similar growth performance, only three of the 
six plants were randomly selected: (a) the first one was used for determination of the biomass; (b) the second one was used for measurement of As in various plant organs; and (c) the third one was used to extract iron plaque.

\subsubsection{Pot Experiment}

A greenhouse experiment was conducted to observe the growth performance of the rice plants and uptake of As by the rice plants. The experiment lasted for more than 9 months, including two continuous crops with a fallow period of about 3 months. The first crop commenced on September 8 , 2013 and the rice plants were harvested on January 7, 2014; the second crop commenced on April 3, 2014 and the rice plants were harvested on July 22, 2014.

The soil without added As was used as the control $(\mathrm{Ck})$; Treatments 1 and 2 (T1 and T2, respectively) were the artificially contaminated soils without and with added Fenton reagent (100 $\mu \mathrm{M} \mathrm{H}_{2} \mathrm{O}_{2}: 100 \mu \mathrm{M} \mathrm{Fe}^{2+}$ ), respectively. The dose of added arsenite-As in the contaminated soils was set at $50 \mathrm{mg} / \mathrm{kg}$. The thickness of the overlying water layer was maintained at approximately $2 \mathrm{~cm}$. For T2, an appropriate amount of standardized $\mathrm{H}_{2} \mathrm{O}_{2}$ and $\mathrm{FeSO}_{4}$ solution was added to the overlying water to maintain a theoretical concentration of $\mathrm{H}_{2} \mathrm{O}_{2}$ and $\mathrm{Fe}^{2+}$ at $100 \mu \mathrm{M}$ each at the beginning of Fenton reagent addition for each 3-day cycle.

Two seedlings were transplanted to a soil column consisting of alternating layers $(1 \mathrm{~cm}$ thick $)$ of quartz sand and a relevant soil material. This design was to allow easy separation of the root materials from the soils upon harvest. The soil column was contained in a nylon mesh bag (\#400 mesh; diameter: $8 \mathrm{~cm}$; depth: $12 \mathrm{~cm}$ ). Four soil columns were placed in a plastic bucket (Diameter: $22 \mathrm{~cm}$; Height: $15 \mathrm{~cm}$ ) that was filled with the same soil material. This design allowed the separation of rhizospheric soil from the bulk soil by confining the rice plant roots within the nylon mesh bag or so-called rhizo-bag. 
Compound fertilizer (N:P:K=15:15:15) was applied at a rate of $19 \mathrm{~g}$ per pot at the $7^{\text {th }}$ day of the experiment. Additional fertilizers were added at a rate of $6.8 \mathrm{~g} / \mathrm{pot}$ for compound fertilizer and 9.6 $\mathrm{g} / \mathrm{pot}$ for urea in the early tillering stage of the first crop. In the second crop, $6.8 \mathrm{~g} / \mathrm{pot}$ and $7 \mathrm{~g} / \mathrm{pot}$ were added 7 days after transplanting of the rice seedlings and in the heading stage, respectively.

In the first crop, one of the four rhizo-bags (together with the above-ground portion) was randomly removed from each bucket in the heading stage. A second rhizo-bag was removed in the maturity stage. For the second crop, sampling was carried out in the tillering, heading and maturity stages. After collection, the soil materials in each rhizo-bag were recovered by separation from the quartz sands. One of the two rice plants from each rhizo-bag was used for measurement of biomass and another one was used for determination of various As species in the plant tissues.

\subsection{Sample Preparation and Analytical Methods}

For biomass measurements, the straw and root portions of the rice plant were separated. The roots were rinsed with water and the excess moisture on the root surfaces was removed using absorbent paper towels. Fresh biomass of the two portions was obtained before they were oven-dried at $60{ }^{\circ} \mathrm{C}$ until constant weight was attained.

For measurements of various As species in plant tissues, different organs of the rice plant (leaf, stem, root and grain) were deep-frozen at $-40{ }^{\circ} \mathrm{C}$ immediately after collection. The samples were then freeze-dried using a VirTis freeze dryer. The dried plant tissue samples were pulverized (For the rice grains, the hulls were removed but no polish was applied prior to pulverization; for the roots, iron plaque was not removed) and then stored at $-20{ }^{\circ} \mathrm{C}$ before being analyzed. Four As species were determined. These include arsenate-As, arsenite-As, monomethylarsonic acid-As (MMA-As) and dimethylarsinic acid-As (DMA-As). Measurements of various As species were performed using a HPLC-ICP-MS system. For HPLC (Agilent1260) separation, Athena C18-WP column and guard 
column were used. The mobile phase was a mixed solution of citric acid and sodium sulfonate. The flow rate was set at $1.0 \mathrm{~mL} / \mathrm{min}$ with an injection volume of $20 \mu \mathrm{L}$. For ICP-MS (Agilent 7700), argon was used as carrier gas and make-up gas. Details on the instrumental operating conditions are given in Supplementary Table S1.

Iron plaque attached on the root surface was extracted by dithionite-citrate-bicarbnate (DCB, Liu et al., 2005). Briefly, fresh roots were rinsed with deionized water and then dried with adsorbent paper towels. For each rhizo-bag, an appropriate amount of root materials were randomly taken and placed in a beaker containing $30 \mathrm{~mL}$ of mixed solution of $0.03 \mathrm{M} \mathrm{Na}_{3} \mathrm{C}_{6} \mathrm{H}_{5} \mathrm{O}_{7} \cdot 2 \mathrm{H}_{2} \mathrm{O}$ and $0.125 \mathrm{M}$ $\mathrm{NaHCO}_{3} .1 \mathrm{~g}$ of $\mathrm{Na}_{2} \mathrm{~S}_{2} \mathrm{O}_{4}$ was then added into the beaker. After mixing, the beaker with its content was allowed to stand for $30 \mathrm{~min}$. The root materials were removed from the beaker and washed with deionized water three times. The extract, together with the spent washing water, was transferred into a $100 \mathrm{~mL}$ volumetric flask, followed by adding an appropriate amount of water to the mark. The washed roots were then oven-dried at $70^{\circ} \mathrm{C}$ to constant weight.

The iron in the DCB extract was determined by atomic absorption spectrometry (ZEEnit $700 \mathrm{P}$ ). Measurements of various As species in the DCB extract were performed using a HPLC-ICP-MS system. The total As in the root plaque was estimated by the sum of various As species.

\subsection{QC/QA and statistical analysis}

The hydroponic culture experiment was performed in 4 replicates and the pot experiment was performed in 3 replicates. The recovery rates of matrix spike for plant tissue samples in the hydroponic experiment were $80.7 \pm 3.51$ for arsenate-As, $92.5 \pm 2.41$ for arsenite-As, $82.2 \pm 2.72$ for MMA-As and 123 \pm 5.98 for DMA-As. The recovery rates of matrix spike for plant tissue samples in the pot experiment were $89.6 \pm 3.43$ for arsenate-As, $105 \pm 3.44$ for arsenite-As, $106 \pm 3.18$ for MMAAs and 122 \pm 6.96 for DMA-As. Statistical difference analysis was performed using One-way 
ANOVA (SPSS17.0).

\section{RESULTS}

\subsection{Hydroponic Culture Experiment}

For both CS1d and CS3d, the concentration of the originally added arsenite-As more or less remained unchanged (Fig. 1). However, for TS1d and TS3d, all the originally added arsenite-As disappeared and arsenate-As was the only As species detected. The concentration of $\mathrm{As}^{5+}$ in the solution was lower than that of arsenite-As originally added into the system. In particular, TS3d only contained about $3.8 \%$ of the originally added As. Iron precipitates were observed to occur on the bottom and wall of the hydroponic containers.

The fresh biomass (either total, shoot or root) of the rice plant was significantly $(p<0.05)$ higher in the treatment than in the control for both the 1-day and the 30-day experiments though for the dry biomass, the difference between the control and the treatment was statistically insignificant for the 1-day experiment (Table 1).

Arsenate-As dominated the As species, followed by arsenite-As. Very small amounts of methylated As species were also detected (Table 1). There was a consistent trend showing that the arsenate-As and DMA-As in the root portion was significantly $(p<0.05)$ higher in the control than in the treatment for both the 1-day experiment and the 30-day experiment while there was no significant difference $(p>0.05)$ in arsenite-As and MMA-As between the control and the treatment for both the 1-day experiment and the 30-day experiment. Overall, the sum of various As species was higher in the control than in the treatment, especially for the leaf portion.

For the stem portion, mixed results were observed. The 1-day experiment showed a higher sum of As species in the control than in the treatment (Table 1). However, the opposite was observed for 
the 30-day experiment. Unlike root portion, arsenite-As dominated As species in the stem portion and methylated As species was detected only in the 1-day experiment. There was no significant $(p>0.05)$ difference in any As specie between the control and the treatment for both the 1-day experiment and the 30-day experiment.

For the leaf portion, there was no significant $(p>0.05)$ difference in any As species between the control and the treatment except for arsenite-As in the 30-day experiment, which showed a significantly $(p<0.05)$ higher value of arsenite-As in the control than in the treatment (Table 1$)$. Similar to the stem portion, arsenite-As dominated As species and no methylated As species were detected in the treatment for the 30-day experiment.

For both the 1-day and 30-day experiments, the total Fe in the root plaque was greater in the treatment than in the control (Table 1). Total As in the root plaque was significantly greater in the treatment than in the control for the 30-day experiment. However, the same was not observed for the 1-day experiment; there was no significant difference in root plaque-borne As between the control and the treatment.

\subsection{Pot Experiment}

As expected, biomass tended to be smaller in the contaminated soils (T1 and T2) than in the control ( $\mathrm{Ck}$, non-contaminated soil) due to As toxicity (Table 2). Comparison shows that treatment of the contaminated soil with Fenton reagent $(\mathrm{T} 2)$ resulted in a significant $(p<0.05)$ increase in biomass, as compared to $\mathrm{T} 1$ for the first crop and the tillering stage of the second crop. For the maturity stage of the first crop, the growth performance was even better in $\mathrm{T} 2$ than in Ck. However, it is interesting to note that there was no significant difference in dry biomass of the shoot portion between $\mathrm{T} 1$ and $\mathrm{T} 2$ for the heading stage of the second crop and the dry biomass of the shoot portion was even greater in $\mathrm{T} 1$ than in $\mathrm{T} 2$ for the maturity stage of the second crop. For the root portion, 
there was no significant difference in the dry biomass among $\mathrm{Ck}, \mathrm{T} 1$ and $\mathrm{T} 2$. In consistent with the biomass, grain yield also tended to be in the following decreasing order: Ck $(10.6 \mathrm{~g})>\mathrm{T} 2(8.0 \mathrm{~g})>$ $\mathrm{T} 1(5.7 \mathrm{~g})$.

The sum of various As species in the root portion was greater in $\mathrm{T} 1$ than in $\mathrm{Ck}$, particularly in the first crop and the tillering stage of the second crop. By comparison, the root-borne As was significantly $(p<0.05)$ less in T2 than in T1 for the heading stage of the first crop and the tillering stage of the second crop. However, no significant $(p>0.05)$ difference in root-borne As between T1 and T2 was observed for the other sampling occasions (Table 3).

Methylated As species only accounted for a small proportion of the root-borne As (Table 3). In most of situations, arsenite-As dominated As species except in $\mathrm{T} 1$ for the heading stage of the first crop and in T1 and T2 for the tillering stage of the second crop when the amount of arsenate-As was close to that of arsenite-As or even slightly greater. One thing in common was that root-borne As tended to be lower in the maturity stage than in the respective earlier growing stages for either arsenite-As or arsenate-As. By comparison, root-borne As at the same growth stage tended to be higher in the first crop than in the second crop for the control and the treatments.

In comparison with the root-borne As, the concentration of As in the stem portion was relatively smaller (Table 4). Like root-borne As, stem-borne As (sum of various As species) also showed a significantly higher value in $\mathrm{T} 1$ than in $\mathrm{Ck}$ for any of the growth stages for the two crops. Unlike the root-borne As, stem-borne As was smaller in T1 than in T2 for the heading stage of the first crop and the tillering stage of the second crop while the opposite was observed for the other three sampling occasions.

The proportion of methylated As species in the sum of As species was generally small except for those in the maturity stage of the first crop (Table 4). For the first crop and the tillering stage of 
the second crop, arsenate-As was greater than did arsenate-As while the opposite was observed for the heading stage and maturity stage of the second crop.

Like the root and stem portions, leaf-borne As (sum of the As species) was consistently greater (significantly at $p<0.05$ ) in $\mathrm{T} 1$ than in $\mathrm{Ck}$ though the difference was not statistically significant in the maturity stage of the second crop (Table 5). For all of the five sampling occasions, there was no significant difference in leaf-borne As between T1 and T2. Like the root and stem portions, methylated As species only took up a small proportion in the sum of various As species. There was a clear trend showing that arsenite-As dominated As species in the heading and maturity stages of the second crop. However, mixed results were observed for other sampling occasions.

The abundance of grain-borne As (sum of various As species) in both the first and second crops had the same pattern: $\mathrm{T} 1>\mathrm{T} 2>\mathrm{Ck}$. This was consistent with the pattern observed for the stem portion in the maturity stage (Fig. 2). By comparison, the concentration of As in the grain portion was consistently higher in the second crop than in the first crop. This was accompanied by the same trend for the stem-borne As. Arsenite-As and DMA-As were the two dominant species. Depending on individual treatments, $\mathrm{Ck}$ had more DMA-As; T2 contained more arsenite-As; and T1 tended to have equal amounts of arsenite-As and DMA-As.

There were orange-colored coating materials (root plaque) on the surfaces of plant roots. However, root coatings did not cover the entire root surface with $\mathrm{T} 1$ tending to have a lower coverage of root plaque, as compared to T2. The abundance of root plaque-borne Fe, as measured by the amount of Fe attached to the surface of per unit of root biomass $(\mathrm{g} / \mathrm{kg})$ in the different stages of rice plant growth for the control and the two treatments is shown in Table 6 . The root plaque-borne Fe tended to be higher in $\mathrm{T} 2$ than in either $\mathrm{T} 1$ or $\mathrm{Ck}$ (significant at $p<0.05$ ). There was a clear trend showing that root plaque-borne As increased from $\mathrm{Ck}$ to $\mathrm{T} 1$ to $\mathrm{T} 2$ for all the five sampling occasions. 


\section{DISCUSSION}

The results obtained from the hydroponic experiment suggest that, under the set experimental conditions, $\mathrm{As}^{3+}$ was resistant to oxidation in the presence of molecular oxygen only. However, addition of Fenton reagent markedly accelerated the oxidation of $\mathrm{As}^{3+}$, resulting in formation of $\mathrm{As}^{5+}$. The decrease in As concentration in the culture solutions suggests that immobilization of As took place. The presence of iron precipitates on the bottom and wall of the hydroponic containers suggests that the $\mathrm{Fe}^{3+}$ formed from Fenton reaction acted as a scavenger to sequester As from the hydroponic solution, resulting in a decrease in solution-borne As. Since the hydroponic nutrient solution contained FeII-EDTA, which is not stable in the presence of oxygen, the Fe from this source could be oxidized to $\mathrm{Fe}^{3+}$, resulting in the formation of iron oxyhydroxide that might add to the plaque (Seibig and and van Eldik, 1997). This was also likely to enhance the local oxidation of $\mathrm{As}^{3+}$ to $\mathrm{As}^{5+}$ (Hug and Leupin, 2003). In addition, the As(III)-oxidizing microbes could also play an important role in oxidizing As on the root iron plaque (Hu et al. 2015).

The generally lower concentration of As in the rice plant tissue in the treatment, relative to the control, can be attributed to the reduced availability of As in the hydroponic solution. The predominant presence of arsenate-As in the root portion appears to suggest that while both arsenate and arsenite might be taken up by the rice seedlings, the uptake of As by root took place more favourably through an arsenate pathway. The change in the predominant As species from arsenateAs to arsenite-As in the above-ground portion reflects the in-plant reduction of arsenate-As (Kramar et al., 2015).

The significantly greater root plaque-borne Fe concentration in the treatment than in the control suggests that addition of Fenton reagent significantly enhanced the formation of iron compounds on 
the root surfaces of the rice plants. Liu et al. (2006) suggested that root plaque-Fe was in mineral forms of iron oxyhydroxides. This work demonstrates that addition of Fenton reagent enhanced the formation of $\mathrm{Fe}^{3+}$-containing chemical compounds on the root surface.

Although no significant difference between the control and the treatment was observed for the 1day experiment, the root plaque-borne As was significantly $(p<0.05)$ greater in the treatment than in the control for the 30-day experiment. This suggests that the addition of Fenton reagent could enhance retention of As by the root plaque. However it took time to incorporate solution-borne As into root plaque and a duration of 24 hours was not sufficient to allow this to take place even when Fenton reagent was added into the system. For the control, transformation of arsenite-As to arsenateAs did not take place and arsenite was the only form of arsenic in the nutrient solution (Fig. 1). Therefore, any arsenate contained in the root plaque was likely to be formed as a result of arsenite oxidation driven by root-released oxygen. For the treatment, production of arsenate was markedly enhanced due to Fenton reaction. From Fig. 1, it is clear that conversion of all arsenite-As into arsenate-As was completed within 1 day after addition of Fenton reagent. The arsenate formed was then gradually removed from the nutrient solution by deposition as iron precipitates and plant uptake.

In the pot experiment, the poorer growth performance, as indicated by smaller biomass in $\mathrm{T} 1 \mathrm{than}$ in Ck during the first crop and the tillering stage of the second crop suggests that an initial dose of As at $50 \mathrm{mg} / \mathrm{kg}$ was sufficient to cause phytotoxicity to the rice plants under the set experimental conditions. Das et al. (2013) observed phytotoxicity to paddy rice at a dose of $40 \mathrm{mg} \mathrm{As} / \mathrm{kg}$, which is very similar to $50 \mathrm{mg} \mathrm{As} / \mathrm{kg}$ in this experiment. The toxic effects of As on rice plant growth became less significant during the heading and maturity stages of the second crop. This may be attributed to reduced bioavailability of the added As due to As immobilization through formation of practically insoluble minerals such as scorodite or adsorption by soil colloids such as Fe oxyhydroxides (Lin and Puls, 2000; Campbell and Nordstrom, 2014; Serrano et al., 2015). Contamination of the soils by 
As led to increased uptake of As by the plants, which impedes the physiological functions of the plants (Hughes, 2002; Islam et al., 2015). However, the application of Fenton reagent effectively reduced this harmful effect and significantly enhanced the growth of the rice plants grown in the Ascontaminated soils. It is interesting to note that the significant increase in biomass in the first crop and the tillering stage of the second crop in T2, as compared to T1, was accompanied by a significant reduction in root-borne As in T2, relative to T1 while the insignificant difference in biomass between $\mathrm{T} 1$ and $\mathrm{T} 2$ in the heading and maturity stages of the second crop was consistent with the insignificant difference in root-borne As between T1 and T2. It is noted that the biomass tended to be greater in the first crop than in the second crop (Table 2). The rice cultivar (TY122) used for the experiment was the one that is more suitable for being grown during the period from autumn to early winter (the first crop) than during the period from late spring to summer (the second crop). In addition, the application rate of chemical fertilizers was relatively lower in the second crop than in the first crop, and this might also affect the growth performance of the rice plants in the second crop.

The relatively low level of root plaque-borne As in $\mathrm{Ck}$ reflected the limited availability of As in the non-contaminated soil. A significantly higher level of root plaque-borne As in T2, as compared to $\mathrm{T} 1$ is attributable to the enhanced formation of iron plaques on the root surfaces of the rice plants due to application of Fenton reagent, which in turn allowed more As being intercepted when As in the soil solution moved towards the surfaces of the plant roots, and consequently reduced the amounts of As being taken by the plant roots.

The trend that $\mathrm{As}_{\text {Stem }} / \mathrm{As}_{\text {Root }}$ and $\mathrm{As}_{\text {leaf }} / \mathrm{As}_{\text {Root }}$ increased over time (Table 7 and Table 8) suggests that the root-to-shoot translocation of As was enhanced as the rice plants became more mature, possibly due to intensified transpiration. The much higher $\mathrm{As}_{\mathrm{Stem}} / \mathrm{As}_{\mathrm{Root}}$ at the maturity stage in the second crop than in the first crop indicates that the efficiency of root-to-stem As translocation was improved due to the reduced As phytotoxicity, which allowed better growth performance of the rice 
plants being achieved. This explains the much higher rice grain-borne As in the second crop than in the first crop.

The capacity of root plaque to impede As flux towards the root surfaces in T1 were limited, leading to substantial uptake of As by the roots. This could also be due to that younger roots and the younger parts of the old roots that play key role in plant uptake of nutrients and metals were hardly coated by iron plaque, as also pointed out by other workers (Seyfferth et al., 2010; Yamaguchi et al., 2014). The addition of Fenton reagent led to production of $\mathrm{Fe}^{3+}$ and hydroxyl radical that enhanced formation of iron precipitates and $\mathrm{As}^{3+}-\mathrm{As}^{5+}$ conversion. This effect was not limited to rhizosphere but also the bulk soils. As demonstrated in the hydroponic experiment, solution-borne arsenite can be oxidized and removed from the culture solution within a relatively short period of time after addition of Fenton reagent. It is therefore likely that arsenite in the soil pore water could experience the same process for the pot experiment. The immobilization of As in the bulk soil could markedly reduce the supply of dissolved As for the plant root, leading to reduced uptake of As by the rice plants. The effect of $\mathrm{FeSO}_{4}$ addition on enhancing formation of iron plaque on rice root surfaces was previously observed by Hossain et al. (2009)

The concentration of As $\left(0.26 \mathrm{mg} / \mathrm{kg}\right.$ for the $1^{\text {st }}$ crop and $0.55 \mathrm{mg} / \mathrm{kg}$ for the $2^{\text {nd }}$ crop $)$ in the grain of rice plants grown in the contaminated soils (T1) far exceeded the maximum limit of 0.1 $\mathrm{mg} / \mathrm{kg}$ set by the European Union for the rice destined for the production of foods for infants and young children (Signes-Pastor et al. 2017) though the level of As could be lower than these values if the rice grains are polished (Meharg et al., 2008). The significant reduction in rice grain-borne As in both the first and second crops due to addition of Fenton reagent sheds some light on the possible role of rainwater-borne $\mathrm{H}_{2} \mathrm{O}_{2}$ in alleviating As contamination in rice grain. In our recent experiment examining the paddy soils receiving natural rainwater containing hydrogen peroxide, a similar effect like what was showed in this microcosm experiment was observed, suggesting that rainwater-borne 
hydrogen peroxide does affect arsenic chemistry in paddy soils (unpublished data). This raises a question on whether rice produced from areas receiving abundant rainfall tends to contain less arsenic. It will be interesting to establish whether there is a relationship between annual rainfall and rice grain-borne As on a global scale.

From a mitigation perspective, the research findings have implications for developing costeffective management strategies and remediation techniques to reduce As uptake by rice plants and accumulation in the rice grain. The uses of industrial grade $\mathrm{H}_{2} \mathrm{O}_{2}$ (US\$500/t, source: Zhengzhou Huize Biochemical Technology Co., Ltd) and $\mathrm{FeSO}_{4}$ (US\$100/t, source: Dalian Future International Co., Ltd.) are not economically prohibitive. A rough calculation based on the experimental design in this study gives an estimated cost of US\$89 per hectare for the purchase of the required chemicals. If appropriate procedure for mixing the Fenton reagent into the irrigation water can be developed, significant reduction of As level in rice grain may be achieved cost-effectively in rice-producing areas where the soils contain high level of As or where As-bearing groundwater is used for irrigation purpose.

\section{Acknowledgements}

This work was partly supported by the research grants from the Natural Science Foundation of China (Project No. 41271469) and under the National High and New Technology Programs (863) of China (Project No. 2013AA102402).

\section{References}

Armstrong, W., 1964. Oxygen diffusion from the roots of some British bog plants. Nature. 204, 801802.

Becker, M., Asch, F., 2005. Iron toxicity in rice conditions and management concepts. J. Plant. Nutr. Soil Sci. 168, 558-573.

Campbell, K.M., Nordstrom, D.K., 2014. Arsenic speciation and sorption in natural environments. 
Chen, Z., Zhu, Y.G., Liu, W.J., Meharg, A.A., 2005. Direct evidence showing the effect of root surface iron plaque on arsenite and arsenate uptake into rice (Oryza sativa) roots. New. Phytol. $165,91-97$.

Clemens, S., Ma, J.F., 2016. Toxic heavy metal and arsenic accumulation in crop plants and foods. Annu. Rev. Plant. Biol. 67, 12.1-12.24.

Cooper, W.J, Zika, R.G., Petasne, R.G., Plane, J. M.C., 1988. Photochemical formation of $\mathrm{H}_{2} \mathrm{O}_{2}$ natural waters exposed to sunlight. Environ. Sci. Technol. 22, 1156-1160.

Das, I., Ghosh, K., Das, D.K., Sanyal, S.K., 2013. Assessment of arsenic toxicity in rice plants in areas of West Bengal. Chem. Spec. Bioavailab. 25(3), 201-208.

Gonçalves, C., Dos Santos, M.A., Fornaroc, A., Pedrotti, J.J., 2010. Hydrogen peroxide in the rainwater of Sao Paulo megacity: measurements and controlling factors. J. Braz. Chem. Soc. 21, 331-339.

Guo, J., Tilgner, A., Yeung, C., Wang, Z., Louie, P.K.K., Luk, C.W.Y., Xu, Z., Yuan, C., Gao, Y., Poon, S., Herrmann, H., Lee, S., Lam, K.S., Wang, T., 2014. Atmospheric peroxides in a polluted subtropical environment: seasonal variation, sources and sinks, and importance of heterogeneous processes. Environ. Sci. Technol. 48, 1443-1450.

Hu, M., Li, F.B., Liu, C.P., Wu, W.J., 2015. The diversity and abundance of As(III) oxidizers on root iron plaque is critical for arsenic bioavailability to rice. Sci. Rep. 5, 13611.

Hug, S.J., Leupin, O., 2003. Iron-catalyzed oxidation of arsenic(III) by oxygen and by hydrogen peroxide: pH-dependent formation of oxidants in the Fenton reaction. Environ. Sci. Technol. 37, 2734-2742.

Hughes, M.F., 2002. Arsenic toxicity and potential mechanisms of action. Toxicol. Lett. 133, 1-16.

Hossain, M.B., Jahiruddin, M., Loeppert, R. H., Panaullah, G.M., Islam, M.R., Duxbury, J.M., 2009. The effects of iron plaque and phosphorus on yield and arsenic accumulation in rice. Plant. Soil. $317,167-176$.

Islam, E., Khan, M.T., Irem, S., 2015. Biochemical mechanisms of signaling: Perspectives in plants under arsenic stress. Ecotox. Environ. Safe. 114, 126-133.

Kramar, U., Norra, S., Berner, Z., Kiczka, M., Chandrasekharam, D., 2015. On the distribution and speciation of arsenic in the soil-plant-system of a rice field in West-Bengal, India: A $\mu$ synchrotron techniques based case study. Appl. Geochem. Available online, 1-11.

Kögel-Knabner, I., Amelung, W., Cao, Z., Fiedler, S., Frenzel, P., Jahn, R., Kalbitz, K., Kölbl, A., Schloter, M., 2010. Biogeochemistry of paddy soils. Geoderma. 157, 1-14.

Lee, C.H., Hsieh, Y.C., Lin, T.H., Lee, D.Y., 2013. Iron plaque formation and its effect on arsenic 
Li, R.Y., Stroud, J.L., Ma, J.F., Mcgrath, S.P., Zhao, F.J., 2009. Mitigation of arsenic accumulation in rice with water management and silicon fertilization. Environ. Sci. Technol. 43, 3778-3783.

Lin, Z., Puls, R.W., 2000. Adsorption, desorption, and oxidation of arsenic affected by clay minerals and aging process. Environ. Geol. 39, 753-759.

Liu, W.J., Zhu, Y.G., Hu, Y., Williams, P.N., Gault, A.G., Meharg, A.A., Charnock, J.M., Smith, F.A., 2006. Arsenic sequestration in iron plaque, its accumulation and speciation in mature rice plants (Oryza Sativa L.). Environ. Sci. Technol. 40, 5730-5736.

Liu, W.J., Zhu, Y.G., Smith, F.A., 2005. Effects of iron and manganese plaques on arsenic uptake by rice seedlings (Oryza sativa L.) grown in solution culture supplied with arsenate and arsenite. Plant. Soil. 227, 127-138.

Meharg, A.A., 2004. Arsenic in rice-understanding a new disaster for South-East Asia. Trends. Plant. Sci. 9, 415-417.

Meharg, A.A., Lombi, E., Williams, P.N., Scheckel, K.G., Feldmann, J., Raab, A., Zhu, Y., Islam, R., 2008. Speciation and localization of arsenic in white and brown rice grains. Environ Sci Technol. 42(4), 1051-1057.

Schoof, R.A., Yost, L.J., Eickhoff, J., Crecelius, E.A., Cragin, D.W., Meacher, D.M., Menzel D.B., 1999. A market basket survey of inorganic arsenic in food. Food. Chem. Toxicol. 37, 839-846.

Serrano, S., Gomez-Gonzalez, M.A., O’Day, P.A., Laborda, F., Bolea, E., Garrido, F., 2015. Arsenic speciation in the dispersible colloidal fraction of soils from a mine-impacted creek. J. Hazard. Mater. 286, 30-40.

Seibig, S., van Eldik, R., 1997. Kinetics of [FeII(edta)] oxidation by molecular oxygen revisited. New evidence for a multistep mechanism. Inorg. Chem. 36, 4115-4120.

Seyfferth, A.L., Webb, S.M., Andrews, J.C., Fendorf, S., 2010. Arsenic localization, speciation, and Co-occurrence with iron on rice (Oryza sativa L.) roots having variable Fe coatings. Environ. Sci. Technol. 44, 8108-8113.

Signes-Pastor A.J., Woodside, J.V., McMullan, P., Mullan, K., Carey, M., Karagas, M.R., Meharg, A.A., 2017. Levels of infants' urinary arsenic metabolites related to formula feeding and weaning with rice products exceeding the EU inorganic arsenic standard. PLoS ONE 12(5), e0176923. https://doi.org/10.1371/journal.pone.0176923

Sinha, B., Bhattacharyya, K., 2015. Arsenic toxicity in rice with special reference to speciation in Indian grain and its implication on human health. J. Sci. Food. Agr. 95, 1435-1444.

Somenahally, A.C., Hollister, E.B., Yan, W.G., Gentry, T.J., Loeppert, R.H., 2011. Water management impacts on arsenic speciation and iron-reducing bacteria in contrasting rice- 
Spanu, A., Daga, L., Orlandoni, A.M., Sanna, G., 2012. The role of irrigation techniques in arsenic bioaccumulation in rice (Oryza sativa L.). Environ. Sci. Technol. 46, 8333-8340.

Su, Y.H., McGrath, S., Zhao, F.J., 2010. Rice is more efficient in arsenite uptake and translocation than wheat and barley. Plant. Soil. 328, 27-34.

Syu, C.H., Huang, C.C., Jiang, P.Y., Lee, C.H., Lee, D.Y., 2015. Arsenic accumulation and speciation in rice grains influenced by arsenic phytotoxicity and rice genotypes grown in arsenic-elevated paddy soils. J. Hazard. Mater. 286, 179-186.

Syu, C.H., Jiang, P.Y., Huang, H.H., Chen, W.T., Lin, T.H., Lee, D.Y., 2013. Arsenic sequestration in iron plaque and its effect on As uptake by rice plants grown in paddy soils with high contents of As, iron oxides, and organic matter. Soil. Sci. Plant. Nutr. 59, 463-471.

Wang, X., Peng, B., Tan, C.Y., Ma, L., Rathinasabapathi, B., 2015. Recent advances in arsenic bioavailability, transport, and speciation in rice. Environ. Sci. Pollut. Res. 22, 5742-5750.

Willey, J.D., Kieber, R.J., Lancaster, R.D., 1996. Coastal rainwater hydrogen peroxide: concentration and deposition. J. Autom. Chem. 25, 149-165.

Williams, P.N., Islam, M.R., Adomako E.E., Raab, A., Hossain, S.A., Zhu, Y.G., Feldmann, J., Meharg, A.A., 2006. Increase in rice grain arsenic for regions of Bangladesh irrigating paddies with elevated arsenic in groundwaters. Environ. Sci. Technol. 40, 4903-4908.

Williams, P.N., Villada, A., Deacon, C., Raab, A., Figuerola, J., Green, A.J., Feldmann, J., Meharg, A.A., 2007. Greatly enhanced arsenic shoot assimilation in rice leads to elevated grain levels compared to wheat and barley. Environ. Sci. Technol. 41, 6854-6859.

Xu, X.Y., Mcgrath, S.P., Meharg, A.A., Zhao, F.J., 2008. Growing rice aerobically markedly decreases arsenic accumulation. Environ. Sci. Technol. 42, 5574-5579.

Yamaguchi, N., Ohkura, T., Takahashi, Y., Maejima, Y., Arao, T., 2014. Arsenic distribution and speciation near rice roots influenced by iron plaques and redox conditions of the soil matrix. Environ. Sci. Technol. 48, 1549-1556.

Zhao, F.J., Ma, J.F., Meharg, A.A., McGrath, S.P., 2009. Arsenic uptake and metabolism in plants. New. Phytol. 181, 777-794.

Zhao, F.J., McGrath, S.P., Meharg, A.A., 2010. Contaminant: mechanisms of plant uptake and metabolism and mitigation strategies, Annu. Rev. Plant. Biol. 61, 535-59.

Zhu, Y.G., Williams, P.N., Meharg, A.A., 2008. Exposure to inorganic arsenic from rice: A global health issue? Environ. Pollut. 154, 169-171.

Zhu, Y.G., Yoshinaga, M., Zhao, F.J. Rosen, B.P., 2014. Earth abides arsenic biotransformations. Annu. Rev. Earth. Planet. Sci. 42, 443-67 


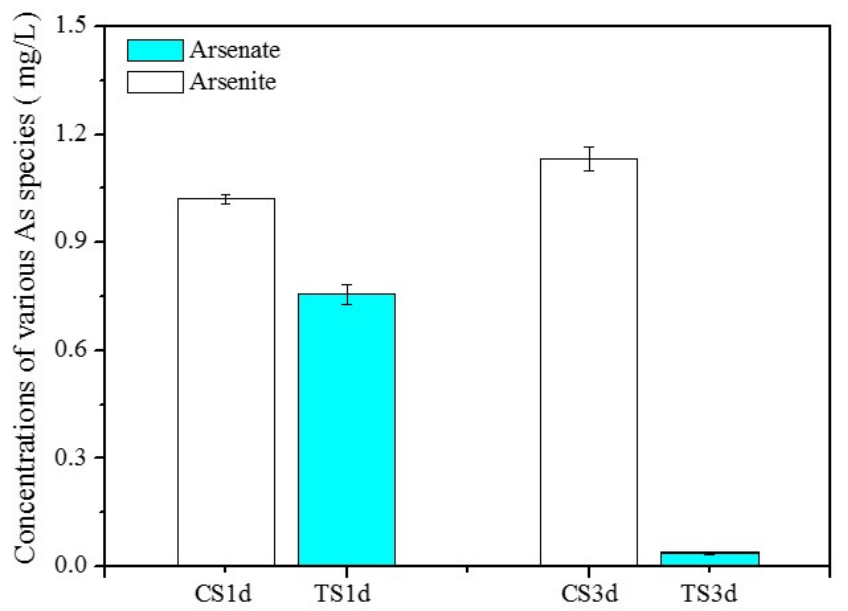

Fig 1 Concentration of various arsenic species in the culture solution in the control (CS) and the treatment (TS) at the end of the 1-day experiment $(24 \mathrm{~h})$ and at the end of the first nutrient replenishment cycle $(\mathbf{7 2} \mathbf{h})$ of the 30-day experiment. All values are presented as mean \pm standard error $(n=4)$. 


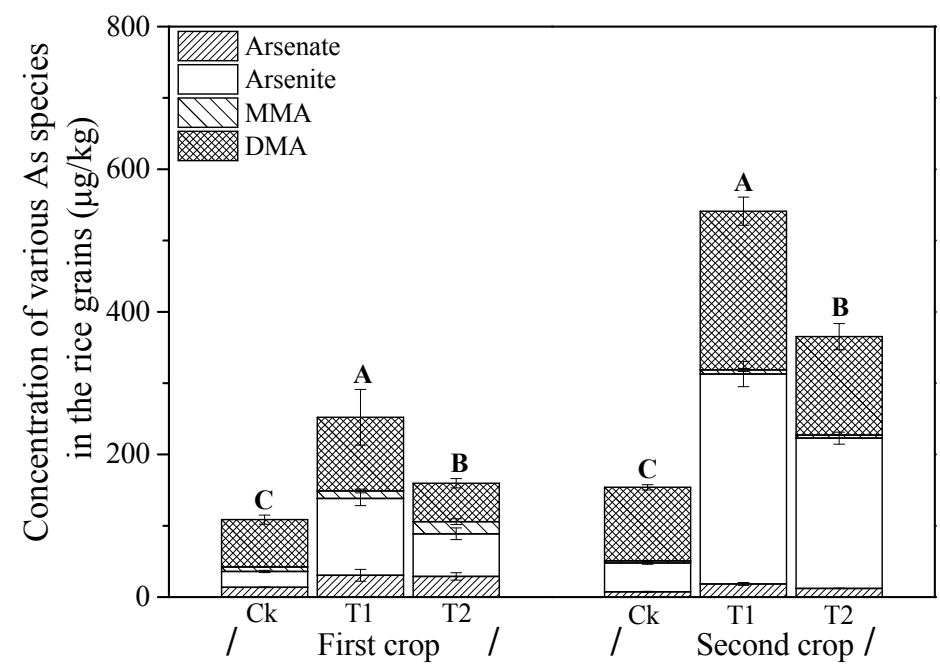

Fig 2 Concentration of various arsenic species in the rice grain harvested in the first crop and second crop for the control (CK) and the two treatments (T1 and T2) in the pot experiment. All values are presented as mean \pm standard error $(n=3)$ and bars with different letters indicate significantly $(P<0.05)$ different means for the sum of various arsenic species (arsenate-As, arseniteAs, MMA-As and DMA-As). 
Table 1 Dry biomass, arsenic species in plant tissues, and iron and arsenic species in root plaque for the 1-day and 30-day hydroponic experiments

\begin{tabular}{llcccc}
\hline & & $\mathrm{C} 1 \mathrm{~d}$ & $\mathrm{~T} 1 \mathrm{~d}$ & $\mathrm{C} 30 \mathrm{~d}$ & $\mathrm{~T} 30 \mathrm{~d}$ \\
\hline Dry biomass $(\mathrm{g})$ & Straw & $0.20 \pm 0.01$ & $0.26 \pm 0.05$ & $0.56 \pm 0.05$ & $0.78 \pm 0.06$ \\
& Root & $0.07 \pm 0.01$ & $0.06 \pm 0.00$ & $0.23 \pm 0.06$ & $0.30 \pm 0.02$ \\
As (root portion, $\mathrm{mg} / \mathrm{kg})$ & Arsenate-As & $98.5 \pm 3.04^{*}$ & $70.0 \pm 1.85$ & $315 \pm 9.74^{*}$ & $238 \pm 6.30$ \\
& Arsenite-As & $18.4 \pm 0.63$ & $18.7 \pm 3.02$ & $59.0 \pm 2.03$ & $59.9 \pm 9.67$ \\
& MMA-As & $2.08 \pm 0.44$ & $0.82 \pm 0.10$ & $4.99 \pm 1.06$ & $1.96 \pm 0.24$ \\
& DMA-As & $3.40 \pm 0.78^{*}$ & $1.65 \pm 0.15$ & $8.84 \pm 2.04^{*}$ & $4.29 \pm 0.38$ \\
& Total As & 122 & 91.1 & 387 & 304 \\
As (stem portion, mg/kg) & Arsenate-As & $5.14 \pm 0.61$ & $4.42 \pm 0.68$ & $15.9 \pm 0.21$ & $19.5 \pm 1.49$ \\
& Arsenite-As & $11.4 \pm 0.73$ & $8.86 \pm 0.63$ & $22.5 \pm 1.70$ & $25.7 \pm 3.29$ \\
& MMA-As & $\mathrm{ND}$ & $\mathrm{ND}$ & $\mathrm{ND}$ & $\mathrm{ND}$ \\
& DMA-As & $1.1 \pm 0.12$ & $0.64 \pm 0.31$ & $\mathrm{ND}$ & $\mathrm{ND}$ \\
& Total As & 17.6 & 13.9 & 38.4 & 45.2 \\
As (leaf portion, $\mathrm{mg} / \mathrm{kg})$ & Arsenate-As & $1.85 \pm 0.38$ & $2.04 \pm 0.26$ & $20.6 \pm 2.56$ & $11.3 \pm 1.47$ \\
& Arsenite-As & $3.13 \pm 0.37$ & $3.48 \pm 0.12$ & $45.7 \pm 6.11^{*}$ & $27.6 \pm 2.69$ \\
& MMA-As & $\mathrm{ND}$ & $\mathrm{ND}$ & $\mathrm{ND}$ & $\mathrm{ND}$ \\
& DMA-As & $0.14 \pm 0.02$ & $0.06 \pm 0.02$ & $\mathrm{ND}$ & $\mathrm{ND}$ \\
& Total As & 5.12 & 5.58 & 66.3 & 38.9 \\
& Total Fe & $5.86 \pm 1.38^{*}$ & $8.29 \pm 0.46$ & $2.00 \pm 0.18^{*}$ & $8.45 \pm 0.58$ \\
Root plaque-Fe $(\mathrm{g} / \mathrm{kg})$ & Total As & $60.9 \pm 1.26$ & $56.2 \pm 1.12$ & $76.6 \pm 0.51^{*}$ & $115 \pm 5.59$ \\
\hline
\end{tabular}

All values are presented as mean \pm standard error $(n=4)$. Independent sample t-test was used to determine whether the two mean values obtained for the control and the treatment differ significantly. Pairs marked with an asterisk indicate significant $(\mathrm{P}<0.05)$ difference between the control and the treatment for each harvest time. ND: not detectable. 
Table 2 Fresh and dry weight (g) of the shoot and root in the first crop and second crop for the control and the two treatments for the pot experiment

\begin{tabular}{llllll}
\hline Growth stage & Treatments & $\begin{array}{c}\text { Shoot } \\
\text { fresh weight }\end{array}$ & $\begin{array}{c}\text { Shoot } \\
\text { dry weight }\end{array}$ & $\begin{array}{c}\text { Root } \\
\text { fresh weight }\end{array}$ & $\begin{array}{c}\text { Root } \\
\text { dry weight }\end{array}$ \\
\hline Heading & $\mathrm{Ck}$ & $47.4 \pm 1.11 \mathrm{a}$ & $8.88 \pm 0.59 \mathrm{a}$ & $20.5 \pm 1.35 \mathrm{a}$ & $4.48 \pm 0.74 \mathrm{a}$ \\
$\left(1^{\text {st }}\right.$ crop) & $\mathrm{T} 1$ & $14.5 \pm 1.32 \mathrm{c}$ & $2.88 \pm 0.3 \mathrm{c}$ & $6.04 \pm 0.97 \mathrm{c}$ & $0.94 \pm 0.21 \mathrm{c}$ \\
& $\mathrm{T} 2$ & $28.8 \pm 1.84 \mathrm{~b}$ & $6.14 \pm 0.27 \mathrm{~b}$ & $13.9 \pm 0.68 \mathrm{~b}$ & $2.76 \pm 0.24 \mathrm{~b}$ \\
Maturity & $\mathrm{Ck}$ & $29.1 \pm 4.20 \mathrm{ab}$ & $14.7 \pm 1.45 \mathrm{a}$ & $24.0 \pm 0.91 \mathrm{~b}$ & $8.52 \pm 0.91 \mathrm{~b}$ \\
$\left(1^{\text {st }}\right.$ crop) & $\mathrm{T} 1$ & $21.1 \pm 0.45 \mathrm{c}$ & $8.24 \pm 1.05 \mathrm{c}$ & $4.11 \pm 0.29 \mathrm{c}$ & $1.64 \pm 0.32 \mathrm{c}$ \\
& $\mathrm{T} 2$ & $31.0 \pm 1.82 \mathrm{a}$ & $13.2 \pm 0.60 \mathrm{ab}$ & $31.0 \pm 4.21 \mathrm{a}$ & $14.6 \pm 1.32 \mathrm{a}$ \\
Tillering & $\mathrm{Ck}$ & $5.40 \pm 0.58 \mathrm{a}$ & $0.71 \pm 0.11 \mathrm{a}$ & $0.52 \pm 0.05 \mathrm{a}$ & $0.12 \pm 0.02 \mathrm{a}$ \\
$2^{\text {nd }}$ crop) & $\mathrm{T} 1$ & $1.57 \pm 0.13 \mathrm{c}$ & $0.23 \pm 0.02 \mathrm{c}$ & $0.14 \pm 0.00 \mathrm{c}$ & $0.07 \pm 0.02 \mathrm{ab}$ \\
& $\mathrm{T} 2$ & $2.75 \pm 0.53 \mathrm{bc}$ & $0.41 \pm 0.09 \mathrm{bc}$ & $0.30 \pm 0.05 \mathrm{bc}$ & $0.08 \pm 0.01 \mathrm{ab}$ \\
Heading & $\mathrm{Ck}$ & $24.7 \pm 2.72 \mathrm{a}$ & $8.07 \pm 1.23 \mathrm{a}$ & $13.3 \pm 1.70 \mathrm{ab}$ & $1.73 \pm 0.17 \mathrm{a}$ \\
$2^{\text {nd }}$ crop) & $\mathrm{T} 1$ & $18.5 \pm 1.29 \mathrm{ab}$ & $6.52 \pm 0.31 \mathrm{ab}$ & $17.8 \pm 0.80 \mathrm{a}$ & $2.12 \pm 0.11 \mathrm{a}$ \\
& $\mathrm{T} 2$ & $16.8 \pm 2.17 \mathrm{~b}$ & $6.42 \pm 0.76 \mathrm{ab}$ & $18.4 \pm 2.01 \mathrm{a}$ & $2.25 \pm 0.64 \mathrm{a}$ \\
Maturity & $\mathrm{Ck}$ & $15.9 \pm 1.46 \mathrm{a}$ & $6.63 \pm 0.68 \mathrm{ab}$ & $14.0 \pm 1.50 \mathrm{a}$ & $1.77 \pm 0.24 \mathrm{a}$ \\
$2^{\text {nd }}$ crop) & $\mathrm{T} 1$ & $16.7 \pm 1.87 \mathrm{a}$ & $7.27 \pm 0.78 \mathrm{a}$ & $11.8 \pm 2.87 \mathrm{a}$ & $2.43 \pm 0.67 \mathrm{a}$ \\
& $\mathrm{T} 2$ & $12.8 \pm 1.68 \mathrm{ab}$ & $4.74 \pm 0.76 \mathrm{~b}$ & $9.36 \pm 0.58 \mathrm{ab}$ & $1.87 \pm 0.12 \mathrm{a}$ \\
\hline
\end{tabular}

All values are presented as mean \pm standard error $(n=3)$ and means with different letters in the same column for each of the five sampling occasions are significantly different $(p<0.05)$. 
Table 3 Concentration $(\mathrm{mg} / \mathrm{kg}$ ) of various As species in the root portion of the rice plant during different growth stages for the pot experiment

\begin{tabular}{lcccccc}
\hline Growth stage & Treatment & Arsenate-As & Arsenite-As & MMA-As & DMA-As & Sum \\
\hline Heading & Ck & $12.7 \pm 2.10 \mathrm{bc}$ & $19.1 \pm 1.94 \mathrm{c}$ & $1.20 \pm 0.14 \mathrm{a}$ & $0.10 \pm 0.01 \mathrm{c}$ & $33.1 \pm 3.74 \mathrm{~b}$ \\
$\left(1^{\text {st }}\right.$ crop) & $\mathrm{T} 1$ & $73.2 \pm 0.78 \mathrm{a}$ & $60.1 \pm 1.57 \mathrm{a}$ & $1.21 \pm 0.12 \mathrm{a}$ & $1.41 \pm 0.22 \mathrm{a}$ & $136 \pm 2.16 \mathrm{a}$ \\
& $\mathrm{T} 2$ & $11.8 \pm 0.37 \mathrm{c}$ & $32.8 \pm 5.95 \mathrm{~b}$ & $0.65 \pm 0.04 \mathrm{~b}$ & $0.79 \pm 0.11 \mathrm{~b}$ & $46.1 \pm 6.16 \mathrm{~b}$ \\
Maturity & $\mathrm{Ck}$ & $1.21 \pm 0.05 \mathrm{c}$ & $7.04 \pm 1.08 \mathrm{c}$ & $0.79 \pm 0.02 \mathrm{c}$ & $0.89 \pm 0.09 \mathrm{ab}$ & $9.93 \pm 1.10 \mathrm{~b}$ \\
$\left(1^{\text {st }}\right.$ crop) & $\mathrm{T} 1$ & $2.03 \pm 0.31 \mathrm{~b}$ & $30.0 \pm 1.56 \mathrm{a}$ & $1.19 \pm 0.15 \mathrm{~b}$ & $0.60 \pm 0.03 \mathrm{~b}$ & $33.8 \pm 1.11 \mathrm{a}$ \\
& $\mathrm{T} 2$ & $3.82 \pm 0.24 \mathrm{a}$ & $22.1 \pm 2.96 \mathrm{~b}$ & $1.52 \pm 0.10 \mathrm{a}$ & $1.28 \pm 0.23 \mathrm{a}$ & $28.7 \pm 3.38 \mathrm{a}$ \\
& $\mathrm{Ck}$ & $8.56 \pm 0.68 \mathrm{c}$ & $11.1 \pm 1.15 \mathrm{~b}$ & $0.03 \pm 0.01 \mathrm{~b}$ & $0.59 \pm 0.03 \mathrm{~b}$ & $20.3 \pm 1.45 \mathrm{c}$ \\
Tillering & $\mathrm{T} 1$ & $82.6 \pm 4.15 \mathrm{a}$ & $85.9 \pm 2.15 \mathrm{a}$ & $2.90 \pm 0.37 \mathrm{a}$ & $2.51 \pm 0.29 \mathrm{a}$ & $174 \pm 6.72 \mathrm{a}$ \\
$\left(2^{\text {nd }}\right.$ crop) & $\mathrm{T} 2$ & $27.8 \pm 1.27 \mathrm{~b}$ & $18.2 \pm 1.26 \mathrm{~b}$ & $0.17 \pm 0.02 \mathrm{~b}$ & $0.66 \pm 0.04 \mathrm{~b}$ & $46.9 \pm 0.38 \mathrm{~b}$ \\
& $\mathrm{Ck}$ & $3.04 \pm 0.39 \mathrm{~b}$ & $14.6 \pm 0.64 \mathrm{~b}$ & $0.14 \pm 0.00 \mathrm{a}$ & $1.33 \pm 0.23 \mathrm{a}$ & $19.1 \pm 0.53 \mathrm{~b}$ \\
Heading & $\mathrm{T} 1$ & $4.91 \pm 0.64 \mathrm{ab}$ & $49.7 \pm 5.64 \mathrm{a}$ & $0.35 \pm 0.05 \mathrm{a}$ & $0.77 \pm 0.17 \mathrm{a}$ & $55.7 \pm 6.11 \mathrm{a}$ \\
$\left(2^{\text {nd }}\right.$ crop) & $\mathrm{T} 2$ & $6.52 \pm 0.94 \mathrm{a}$ & $52.4 \pm 2.92 \mathrm{a}$ & $0.22 \pm 0.01 \mathrm{a}$ & $1.27 \pm 0.23 \mathrm{a}$ & $60.4 \pm 4.01 \mathrm{a}$ \\
& $\mathrm{Ck}$ & $1.60 \pm 0.21 \mathrm{a}$ & $4.94 \pm 0.32 \mathrm{c}$ & $0.34 \pm 0.04 \mathrm{~b}$ & $0.50 \pm 0.08 \mathrm{~b}$ & $7.38 \pm 0.57 \mathrm{~b}$ \\
Maturity & $\mathrm{T} 1$ & $1.89 \pm 0.55 \mathrm{a}$ & $9.30 \pm 0.69 \mathrm{~b}$ & $1.42 \pm 0.20 \mathrm{a}$ & $0.73 \pm 0.13 \mathrm{ab}$ & $13.3 \pm 1.05 \mathrm{a}$ \\
$\left(2^{\text {nd }}\right.$ crop) & $\mathrm{T} 2$ & $1.61 \pm 0.39 \mathrm{a}$ & $12.4 \pm 1.06 \mathrm{a}$ & $0.82 \pm 0.04 \mathrm{ab}$ & $0.88 \pm 0.05 \mathrm{a}$ & $15.7 \pm 1.43 \mathrm{a}$ \\
&
\end{tabular}

All values are presented as mean \pm standard error $(n=3)$ and means with different letters in the same column for each of the five sampling occasions are significantly different $(p<0.05)$. 
Table 4 Concentration $(\mathrm{mg} / \mathrm{kg})$ of various As species in the stem portion of the rice plant during different growth stages for the pot experiment

\begin{tabular}{|c|c|c|c|c|c|c|}
\hline Growth stage & Treatment & Arsenate & Arsenite & MMA & DMA & Sum \\
\hline Heading & $\mathrm{Ck}$ & $1.40 \pm 0.09 \mathrm{c}$ & $1.02 \pm 0.13 \mathrm{c}$ & $0.19 \pm 0.01 b$ & $0.13 \pm 0.01 \mathrm{c}$ & $2.74 \pm 0.15 c$ \\
\hline \multirow{2}{*}{ ( $1^{\text {st }}$ crop) } & $\mathrm{T} 1$ & $6.47 \pm 0.82 \mathrm{ab}$ & $4.03 \pm 0.29 \mathrm{ab}$ & $0.28 \pm 0.01 \mathrm{ab}$ & $0.44 \pm 0.07 \mathrm{~b}$ & $11.2 \pm 0.49 b$ \\
\hline & $\mathrm{T} 2$ & $7.70 \pm 0.48 \mathrm{a}$ & $5.12 \pm 0.16 \mathrm{a}$ & $0.34 \pm 0.00 \mathrm{a}$ & $0.60 \pm 0.01 \mathrm{a}$ & $13.7 \pm 0.35 \mathrm{a}$ \\
\hline Maturity & $\mathrm{Ck}$ & $2.16 \pm 0.21 b$ & $1.58 \pm 0.20 \mathrm{ab}$ & $0.36 \pm 0.06 \mathrm{c}$ & $0.47 \pm 0.03 \mathrm{c}$ & $4.57 \pm 0.22 \mathrm{c}$ \\
\hline \multirow[t]{2}{*}{ ( $1^{\text {st }}$ crop) } & $\mathrm{T} 1$ & $3.75 \pm 0.30 \mathrm{a}$ & $2.28 \pm 0.13 \mathrm{a}$ & $1.30 \pm 0.21 \mathrm{a}$ & $1.54 \pm 0.16 \mathrm{a}$ & $8.87 \pm 0.34 \mathrm{a}$ \\
\hline & $\mathrm{T} 2$ & $3.01 \pm 0.21 \mathrm{ab}$ & $1.84 \pm 0.06 \mathrm{ab}$ & $0.94 \pm 0.07 \mathrm{ab}$ & $1.26 \pm 0.1 \mathrm{ab}$ & $7.06 \pm 0.08 b$ \\
\hline Tillering & $\mathrm{Ck}$ & $0.43 \pm 0.07 \mathrm{c}$ & $0.34 \pm 0.03 b$ & $0.00 \pm 0.00 \mathrm{ab}$ & $0.04 \pm 0.00 \mathrm{a}$ & $0.80 \pm 0.05 \mathrm{c}$ \\
\hline \multirow[t]{2}{*}{ ( $2^{\text {nd }}$ crop) } & $\mathrm{T} 1$ & $1.33 \pm 0.30 \mathrm{~b}$ & $0.55 \pm 0.01 \mathrm{a}$ & $0.03 \pm 0.00 \mathrm{a}$ & $0.04 \pm 0.00 \mathrm{a}$ & $1.94 \pm 0.30 \mathrm{~b}$ \\
\hline & $\mathrm{T} 2$ & $2.45 \pm 0.13 \mathrm{a}$ & $0.64 \pm 0.08 \mathrm{a}$ & $0.02 \pm 0.00 \mathrm{ab}$ & $0.07 \pm 0.00 \mathrm{a}$ & $3.17 \pm 0.06 \mathrm{a}$ \\
\hline & $\mathrm{Ck}$ & $0.56 \pm 0.13 \mathrm{ab}$ & $7.03 \pm 0.78 \mathrm{c}$ & $0.03 \pm 0.00 \mathrm{~b}$ & $0.06 \pm 0.00 \mathrm{~b}$ & $7.68 \pm 0.81 \mathrm{c}$ \\
\hline \multirow[t]{2}{*}{ ( $2^{\text {nd }}$ crop) } & $\mathrm{T} 1$ & $0.88 \pm 0.19 \mathrm{a}$ & $18.21 \pm 1.77 \mathrm{a}$ & $0.08 \pm 0.02 \mathrm{a}$ & $0.23 \pm 0.03 \mathrm{a}$ & $19.3 \pm 1.84 \mathrm{a}$ \\
\hline & $\mathrm{T} 2$ & $0.57 \pm 0.03 \mathrm{ab}$ & $12.58 \pm 1.02 b$ & $0.05 \pm 0.02 \mathrm{ab}$ & $0.24 \pm 0.05 \mathrm{a}$ & $13.4 \pm 0.93 b$ \\
\hline & $\mathrm{Ck}$ & $0.57 \pm 0.22 \mathrm{a}$ & $8.78 \pm 0.55 b$ & $0.03 \pm 0.00 \mathrm{a}$ & $0.08 \pm 0.02 \mathrm{ab}$ & $9.46 \pm 0.60 \mathrm{~b}$ \\
\hline \multirow[t]{2}{*}{ ( $\left.2^{\text {nd }} \mathrm{crop}\right)$} & $\mathrm{T} 1$ & $0.67 \pm 0.06 \mathrm{a}$ & $20.46 \pm 2.65 a$ & $0.05 \pm 0.02 \mathrm{a}$ & $0.23 \pm 0.06 \mathrm{a}$ & $21.4 \pm 2.78 \mathrm{a}$ \\
\hline & $\mathrm{T} 2$ & $0.91 \pm 0.37 \mathrm{a}$ & $10.75 \pm 2.19 b$ & $0.03 \pm 0.00 \mathrm{a}$ & $0.18 \pm 0.00 \mathrm{a}$ & $11.8 \pm 2.52 b$ \\
\hline
\end{tabular}

All values are presented as mean \pm standard error $(n=3)$ and means with different letters in the same column for each of the five sampling occasions are significantly different $(p<0.05)$. 
Table 5 Concentration $(\mathrm{mg} / \mathrm{kg}$ ) of various As species in the leaf portion of the rice plant during different growth stages for the pot experiment

\begin{tabular}{lcllllc}
\hline Growth stage & Treatment & Arsenate-As & Arsenite-As & MMA-As & DMA-As & Sum \\
\hline Heading & Ck & $1.64 \pm 0.16 \mathrm{~b}$ & $1.76 \pm 0.22 \mathrm{c}$ & $0.08 \pm 0.01 \mathrm{a}$ & $0.06 \pm 0.01 \mathrm{~b}$ & $3.53 \pm 0.33 \mathrm{~b}$ \\
$\left(1^{\text {st }}\right.$ crop) & T1 & $5.16 \pm 0.36 \mathrm{a}$ & $3.48 \pm 0.56 \mathrm{ab}$ & $0.09 \pm 0.01 \mathrm{a}$ & $0.23 \pm 0.03 \mathrm{~b}$ & $8.97 \pm 0.87 \mathrm{a}$ \\
& $\mathrm{T} 2$ & $4.45 \pm 0.38 \mathrm{a}$ & $3.83 \pm 0.33 \mathrm{a}$ & $0.11 \pm 0.02 \mathrm{a}$ & $0.88 \pm 0.07 \mathrm{a}$ & $9.27 \pm 0.36 \mathrm{a}$ \\
Maturity & Ck & $1.87 \pm 0.18 \mathrm{c}$ & $1.66 \pm 0.07 \mathrm{c}$ & $0.09 \pm 0.02 \mathrm{a}$ & $0.15 \pm 0.01 \mathrm{~b}$ & $3.77 \pm 0.13 \mathrm{~b}$ \\
$\left(1^{\text {st }}\right.$ crop) & T1 & $4.10 \pm 0.29 \mathrm{a}$ & $4.81 \pm 0.42 \mathrm{ab}$ & $0.08 \pm 0.01 \mathrm{a}$ & $0.28 \pm 0.01 \mathrm{a}$ & $9.27 \pm 0.66 \mathrm{a}$ \\
& T2 & $2.94 \pm 0.31 \mathrm{~b}$ & $5.40 \pm 0.42 \mathrm{a}$ & $0.12 \pm 0.02 \mathrm{a}$ & $0.12 \pm 0.02 \mathrm{~b}$ & $8.58 \pm 0.64 \mathrm{a}$ \\
Tillering & Ck & $1.70 \pm 0.07 \mathrm{c}$ & $2.40 \pm 0.20 \mathrm{ab}$ & $0.04 \pm 0.00 \mathrm{a}$ & $0.06 \pm 0.00 \mathrm{ab}$ & $4.19 \pm 0.18 \mathrm{~b}$ \\
$\left(2^{\text {nd }}\right.$ crop) & T1 & $3.73 \pm 0.28 \mathrm{~b}$ & $4.47 \pm 0.81 \mathrm{a}$ & $0.05 \pm 0.00 \mathrm{a}$ & $0.15 \pm 0.01 \mathrm{a}$ & $8.41 \pm 1.08 \mathrm{a}$ \\
& T2 & $5.57 \pm 0.50 \mathrm{a}$ & $3.04 \pm 0.57 \mathrm{a}$ & $0.05 \pm 0.01 \mathrm{a}$ & $0.09 \pm 0.01 \mathrm{a}$ & $8.76 \pm 1.03 \mathrm{a}$ \\
Heading & Ck & $0.11 \pm 0.01 \mathrm{~b}$ & $1.14 \pm 0.06 \mathrm{~b}$ & $0.00 \pm 0.00 \mathrm{~b}$ & $0.02 \pm 0.00 \mathrm{~b}$ & $1.26 \pm 0.07 \mathrm{~b}$ \\
$\left(2^{\text {nd }}\right.$ crop) & T1 & $0.15 \pm 0.01 \mathrm{ab}$ & $1.88 \pm 0.18 \mathrm{a}$ & $0.02 \pm 0.00 \mathrm{a}$ & $0.05 \pm 0.01 \mathrm{a}$ & $2.10 \pm 0.19 \mathrm{a}$ \\
& T2 & $0.19 \pm 0.02 \mathrm{a}$ & $2.08 \pm 0.21 \mathrm{a}$ & $0.01 \pm 0.00 \mathrm{ab}$ & $0.04 \pm 0.01 \mathrm{ab}$ & $2.32 \pm 0.21 \mathrm{a}$ \\
Maturity & Ck & $1.13 \pm 0.25 \mathrm{a}$ & $7.20 \pm 0.85 \mathrm{ab}$ & $0.14 \pm 0.03 \mathrm{ab}$ & $0.25 \pm 0.04 \mathrm{~b}$ & $8.72 \pm 1.10 \mathrm{a}$ \\
$\left(2^{\text {nd }}\right.$ crop) & T1 & $2.22 \pm 1.14 \mathrm{a}$ & $8.65 \pm 1.00 \mathrm{a}$ & $0.27 \pm 0.03 \mathrm{a}$ & $0.82 \pm 0.09 \mathrm{a}$ & $11.9 \pm 0.45 \mathrm{a}$ \\
& T2 & $2.22 \pm 0.49 \mathrm{a}$ & $7.97 \pm 0.51 \mathrm{a}$ & $0.15 \pm 0.02 \mathrm{ab}$ & $0.80 \pm 0.05 \mathrm{a}$ & $11.1 \pm 1.00 \mathrm{a}$ \\
\hline
\end{tabular}

All values are presented as mean \pm standard error $(n=3)$ and means with different letters in the same column for each of the five sampling occasions are significantly different $(p<0.05)$. 
Table 6 Concentration of total iron and arsenic in the iron plaque of root surface during different growth stages for the pot experiment

\begin{tabular}{llcc}
\hline Growth stage & Treatments & Total Fe $(\mathrm{g} / \mathrm{kg})$ & Total As $(\mathrm{mg} / \mathrm{kg})$ \\
\hline Heading & $\mathrm{Ck}$ & $1.61 \pm 0.10 \mathrm{c}$ & $19.1 \pm 4.84 \mathrm{c}$ \\
$\left(1^{\text {st }}\right.$ crop) & $\mathrm{T} 1$ & $2.34 \pm 0.15 \mathrm{bc}$ & $29.7 \pm 4.19 \mathrm{~b}$ \\
& $\mathrm{~T} 2$ & $21.35 \pm 1.44 \mathrm{a}$ & $55.4 \pm 12.0 \mathrm{a}$ \\
Maturity & $\mathrm{Ck}$ & $15.00 \pm 0.60 \mathrm{a}$ & $73.7 \pm 18.5 \mathrm{c}$ \\
$\left(1^{\text {st }}\right.$ crop) & $\mathrm{T} 1$ & $11.30 \pm 0.36 \mathrm{~b}$ & $330 \pm 20.5 \mathrm{~b}$ \\
& $\mathrm{~T} 2$ & $15.50 \pm 0.49 \mathrm{a}$ & $711 \pm 37.1 \mathrm{a}$ \\
Tillering & $\mathrm{Ck}$ & $17.79 \pm 0.51 \mathrm{a}$ & $235 \pm 3.35 \mathrm{c}$ \\
$2^{\text {nd }}$ crop) & $\mathrm{T} 1$ & $9.79 \pm 0.57 \mathrm{~b}$ & $526 \pm 20.6 \mathrm{~b}$ \\
& $\mathrm{~T} 2$ & $19.43 \pm 1.32 \mathrm{a}$ & $980 \pm 38.2 \mathrm{a}$ \\
Heading & $\mathrm{Ck}$ & $28.28 \pm 3.73 \mathrm{a}$ & $175 \pm 8.86 \mathrm{c}$ \\
$\left(2^{\text {nd }}\right.$ crop) & $\mathrm{T} 1$ & $16.42 \pm 0.57 \mathrm{~b}$ & $562 \pm 13.5 \mathrm{~b}$ \\
& $\mathrm{~T} 2$ & $25.62 \pm 1.10 \mathrm{a}$ & $707 \pm 38.8 \mathrm{a}$ \\
Maturity & $\mathrm{Ck}$ & $17.52 \pm 0.98 \mathrm{ab}$ & $173 \pm 4.98 \mathrm{c}$ \\
$2^{\text {nd }}$ crop) & $\mathrm{T} 1$ & $15.57 \pm 0.43 \mathrm{~b}$ & $297 \pm 3.28 \mathrm{~b}$ \\
& $\mathrm{~T} 2$ & $20.07 \pm 1.17 \mathrm{a}$ & $579 \pm 15.6 \mathrm{a}$ \\
\hline
\end{tabular}

All values are presented as mean \pm standard error $(n=3)$ and means with different letters in the same column for each of the five sampling occasions are significantly different $(p<0.05)$. 
Table 7 The ratios of stem-borne As to root-borne $A s\left(\mathrm{As}_{S t e m} / \mathrm{As}_{\mathrm{Root}}\right)$ in the different growth stages of rice plants for the control and the treatments for the pot experiment

\begin{tabular}{llccccc}
\hline Growth stage & Treatment & Arsenate-As & Arsenite-As & MMA-As & DMA-As & Sum \\
\hline Heading (1 ${ }^{\text {st }}$ crop) & Ck & 0.110 & 0.053 & 0.158 & 1.300 & 0.083 \\
& T1 & 0.088 & 0.067 & 0.231 & 0.312 & 0.082 \\
& T2 & 0.651 & 0.156 & 0.523 & 0.759 & 0.298 \\
Mature (1 ${ }^{\text {st }}$ crop) & Ck & 1.785 & 0.224 & 0.456 & 0.528 & 0.460 \\
& T1 & 1.847 & 0.076 & 1.092 & 2.567 & 0.262 \\
Tillering (2nd crop) & T2 & 0.788 & 0.083 & 0.618 & 0.984 & 0.245 \\
& Ck & 0.050 & 0.030 & 0.000 & 0.068 & 0.039 \\
& T1 & 0.016 & 0.006 & 0.010 & 0.016 & 0.011 \\
Heading (2nd crop) & T2 & 0.088 & 0.035 & 0.118 & 0.106 & 0.068 \\
& T1 & 0.184 & 0.481 & 0.214 & 0.045 & 0.401 \\
& T2 & 0.179 & 0.366 & 0.229 & 0.299 & 0.348 \\
Mature (2 ${ }^{\text {nd }}$ crop) & Ck & 0.087 & 0.240 & 0.227 & 0.189 & 0.223 \\
& T1 & 0.356 & 1.777 & 0.088 & 0.160 & 1.282 \\
& T2 & 0.354 & 2.200 & 0.035 & 0.315 & 1.606 \\
& & 0.565 & 0.866 & 0.037 & 0.205 & 0.753 \\
\hline
\end{tabular}


Table 8 The ratios of leaf-borne As to root-borne $A s\left(A s_{\text {leaf }} / A s_{\text {Root }}\right)$ in the different growth stages of rice plants for the control and the treatments for the pot experiment

\begin{tabular}{lcccccc}
\hline Growth stage & Treatment & Arsenate-As & Arsenite-As & MMA-As & DMA-As & Total \\
\hline Heading $\left(1^{\text {st }}\right.$ crop) & Ck & 0.128 & 0.092 & 0.067 & 0.600 & 0.106 \\
& T1 & 0.070 & 0.058 & 0.074 & 0.163 & 0.066 \\
Mature ( $1^{\text {st }}$ crop) & T2 & 0.376 & 0.116 & 0.169 & 1.114 & 0.201 \\
& Ck & 1.545 & 0.236 & 0.114 & 0.169 & 0.380 \\
& T1 & 2.020 & 0.160 & 0.067 & 0.467 & 0.274 \\
Tillering (2 & T2 & 0.770 & 0.244 & 0.079 & 0.094 & 0.298 \\
& Ck & 0.199 & 0.215 & 1.333 & 0.102 & 0.206 \\
Heading $\left(2^{\text {nd }}\right.$ crop) & T1 & 0.045 & 0.052 & 0.017 & 0.060 & 0.048 \\
& T2 & 0.200 & 0.166 & 0.294 & 0.136 & 0.187 \\
& Ck & 0.036 & 0.078 & 0.000 & 0.015 & 0.066 \\
Mature $\left(2^{\text {nd }}\right.$ crop) & T1 & 0.031 & 0.038 & 0.057 & 0.065 & 0.038 \\
& T2 & 0.029 & 0.040 & 0.045 & 0.031 & 0.038 \\
& Ck & 0.706 & 1.457 & 0.412 & 0.500 & 1.182 \\
& T1 & 1.175 & 0.930 & 0.190 & 1.123 & 0.896 \\
& T2 & 1.379 & 0.642 & 0.183 & 0.909 & 0.708 \\
\hline
\end{tabular}




\section{Highlights}

- Hydroponic and pot experiments were conducted in arsenic-contaminated systems

- The effects of Fenton reagent on immobilization of arsenic were examined

- Fenton process enhanced the growth of rice plants in arsenic -contaminated systems

- As uptake by rice plant was impeded leading to reduced level of As in rice grain

- Implications for minimizing human health risk from consumption of As-rich rice 


\title{
Fenton Reagent Reduces the Level of Arsenic in Paddy Rice Grain
}

\author{
Junhao Qin 1,2, Yongjun $\mathrm{Li}^{3}$, Minling Feng ${ }^{3}$, Huashou $\mathrm{Li}^{1 *}$ and Chuxia Lin ${ }^{2 *}$ \\ ${ }^{1}$ College of Natural Resources and Environment, South China Agricultural University, Guangzhou, \\ China
}

${ }^{2}$ School of Environment and Life Science, University of Salford, Greater Manchester M5 4WT United Kingdom

${ }^{3}$ Zhongshan Quality Supervision and Inspection Institute of Agricultural Products, Zhongshan, China

*Corresponding authors: $\underline{\text { C.Lin@ } @ \text { salford.ac.uk; lihuashou@scau.edu.cn }}$ 


\begin{abstract}
Hydroponic and pot experiments were conducted to examine the effects of Fenton reagent on paddy rice plant growing in arsenic-contaminated soils. Fenton reagent significantly reduced arsenic phytotoxicity, uptake by the plants and accumulation in rice grain. This is attributed to oxidation of $\mathrm{As}^{3+}$ to $\mathrm{As}^{5+}$ by hydroxyl radicals and immobilization of arsenate by reacting with precipitating $\mathrm{Fe}^{3+}$ to form practically insoluble compounds. Although this process enhanced the formation of Feenriched coatings on root surface, it appears that root plaque had limited effects on inhibiting As uptake since most of the young roots were not covered by iron plaque. It is more likely that As immobilization in the bulk soils play a major role in reducing As flux towards rhizosphere. The findings have implications for understanding As behavior in paddy field receiving rainwater-borne hydrogen peroxide and developing cost-effective techniques for reducing As level in rice grain produced from As-contaminated soils.
\end{abstract}

Keywords: Paddy rice, arsenic, iron plaque, soil, Fenton reaction 


\section{$1 \quad$ INTRODUCTION}

Consumption of rice is a major pathway of human arsenic exposure, which could affect billions of people around the world (Schoof et al., 1999; Meharg, 2004; Williams et al., 2006; Zhu et al., 2008; Syu et al., 2015; Sinha and Bhattacharyya, 2015; Clemens and Ma, 2016). The anaerobic soil conditions associated with water inundation required for paddy rice farming favour reduction reactions, leading to formation of highly toxic arsenite ions (Xu et al., 2008; Li et al., 2009; Somenahally et al., 2011; Spanu et al., 2012). Arsenite tends to be predominantly present in undissociated form $\left(\mathrm{H}_{3} \mathrm{AsO}_{3}{ }^{\circ}\right)$ under $\mathrm{pH}$ conditions encountered in most paddy rice soils (Zhao et al., 2009), and therefore it may be more resistant to immobilization by soil adsorbents. In addition, under reducing conditions the arsenic-scavenging capacity of soil is weakened due to reductive dissolution of various iron compounds that play a key role in binding soluble arsenic species through either formation of practically insoluble iron arsenate minerals or adsorption of arsenate to iron oxyhydroxides (Zhao et al., 2010; Zhu et al., 2014). As such, arsenite is readily available for uptake by rice plants and accumulation in rice grain (Williams et al., 2007; Su et al., 2010; Wang et al., 2015).

Iron-enriched root plaque plays an important role in reducing the entry of As present in the soil pore water (soil solution) into rice plant roots (Lee et al., 2013; Syu et al., 2013). The formation of root plaque is believed to be mediated by oxidation of ferrous iron $\left(\mathrm{Fe}^{2+}\right)$ using molecular oxygen released from rice plant roots (Armstrong, 1964), and it is likely that the root-released oxygen also promotes microbially mediated oxidation of arsenite to form arsenate (Hu et al., 2015). As arsenate has the stronger affinity to $\mathrm{Fe}^{3+}$, it is likely that arsenate-As tends to be intercepted more easily by the root plaque, as compared to arsenite-As (Chen et al., 2005; Liu et al., 2005).

It has been demonstrated that Fenton process involving reaction between hydrogen peroxide $\left(\mathrm{H}_{2} \mathrm{O}_{2}\right)$ and ferrous iron $\left(\mathrm{Fe}^{2+}\right)$ resulted in enhanced oxidation of arsenite to form less toxic arsenate 
(Hug and Leupin, 2003). $\mathrm{Fe}^{2+}$ is available in flooded soils like paddy rice soils (Becker and Asch, 2005; Kögel-Knabner et al., 2010). $\mathrm{H}_{2} \mathrm{O}_{2}$ is also commonly present in rainwater (Cooper et al., 1988; Willey et al., 1996; Gonçalves et al., 2010; Guo et al., 2014). In areas with abundant rainfall, Fenton reaction may be a naturally-occurring process that can affect the biogeochemical behaviour of arsenic in paddy rice soils. Where the enrichment of arsenic in rice grain becomes a significant health concern, it may be worthwhile to consider the use of Fenton reagent (a mixture of $\mathrm{H}_{2} \mathrm{O}_{2}$ and $\mathrm{Fe}^{2+}$ ) for reducing As uptake by rice plants.

The objective of this study was to examine the effects of Fenton reagent on reducing As uptake by rice plants. The impacts of Fenton reagent on plant growth are also evaluated. In addition, the major biogeochemical mechanisms responsible for the observed phenomena are explored.

\section{MATERIALS AND METHODS}

\subsection{Materials}

\subsubsection{Hydroponic Nutrient Solution}

The hydroponic nutrient solution used for the solution culture experiment consisted of the following chemical compounds: $5 \mathrm{mM} \mathrm{NH}_{4} \mathrm{NO}_{3}, 2 \mathrm{mM} \mathrm{K}_{2} \mathrm{SO}_{4}, 4 \mathrm{mM} \mathrm{CaCl} 2,1.5 \mathrm{mM} \mathrm{MgSO} 4 \cdot 7 \mathrm{H}_{2} \mathrm{O}$, $1.3 \mathrm{mM} \mathrm{KH}_{2} \mathrm{PO}_{4}, 50 \mu \mathrm{M} \mathrm{Fe}(\mathrm{II})$ )-ethylenediaminetetraacetic acid (EDTA), $10 \mu \mathrm{M} \mathrm{H}_{3} \mathrm{BO}_{4}, 1.0 \mu \mathrm{M}$ $\mathrm{ZnSO}_{4} \cdot 7 \mathrm{H}_{2} \mathrm{O}, 1.0 \mu \mathrm{M} \mathrm{CuSO} \cdot 5 \mathrm{H}_{2} \mathrm{O}, 5.0 \mu \mathrm{M} \mathrm{MnSO} \cdot \cdot \mathrm{H}_{2} \mathrm{O}, 0.5 \mu \mathrm{M} \mathrm{Na} \mathrm{MoO}_{4} \cdot 2 \mathrm{H}_{2} \mathrm{O}$, and $0.2 \mu \mathrm{M}$ $\mathrm{CoSO}_{4} \cdot 7 \mathrm{H}_{2} \mathrm{O}$. The $\mathrm{pH}$ of the solution was adjusted to 5.5 using $0.1 \mathrm{M} \mathrm{KOH}$ or $\mathrm{HCl}$.

\subsubsection{The Experimental Soil}

The soil sample used for the greenhouse experiment was taken from the paddy rice field of the experimental farm at the South China Agricultural University (Guangzhou, China). The soil samples were air-dried after collection and then crushed to pass a $2 \mathrm{~mm}$ sieve prior to the use in the 
experiments. The soil had a $\mathrm{pH}$ of 6.52 and contained $2.38 \%$ of organic matter. Total nitrogen, phosphorus and potassium were 1.06, 1.04 and $19.6 \mathrm{~g} / \mathrm{kg}$, respectively. Available nitrogen, phosphorus and potassium were 114, 77.8 and $122 \mathrm{mg} / \mathrm{kg}$, respectively. The soil contained 15.6 $\mathrm{mg} / \mathrm{kg}$ of arsenate-As and no other arsenic species were detected.

\subsubsection{The Rice Seedlings Used in the Experiment}

The seeds of rice (Oryza sativa cultivar: Tianyou 122) used in the experiment were provided by the Guangdong Academy of Agricultural Sciences. Prior to sowing, the seeds were surfacesterilized by soaking in $30 \% \mathrm{H}_{2} \mathrm{O}_{2}$ for $15 \mathrm{~min}$. The sterilized seeds were then rinsed with deionized water and placed in a container with moistened sands for germination. The pre-germinated seeds were sown into the seed bed that was covered by a plastic sheet to maintain the temperature at $28 \pm$ $2{ }^{\circ} \mathrm{C}$. Healthy seedlings with 4 leaves were selected for the experiment.

\subsection{Experimental Design}

\subsubsection{Solution Culture Experiment}

The rice seedlings were grown in the hydroponic nutrient solution for 3 weeks. The seedlings were then rinsed with deionized water and transplanted into a beaker containing $500 \mathrm{~mL}$ of $20 \mathrm{mg}$ $\mathrm{Fe}^{2+} / \mathrm{L}$ solution ( $\mathrm{pH}$ being adjusted to 5.5 ) for $24 \mathrm{~h}$ to allow the formation of iron plaques on the root surfaces of the seedlings. After this, the seedlings were rinsed to remove any soluble Fe attached to the plant surface before being used in the experiments.

Two sets of the experiments were performed aiming to collect data at the end of two different lengths of growth period: 1 day $(24 \mathrm{~h})$ and 30 days $(720 \mathrm{~h})$. For each set of the experiment, one control and one treatment were set; (a) control: plant growing in the hydroponic nutrient solution with added arsenite-As at a dose of $1 \mathrm{mg} / \mathrm{L}$; (c) Treatment: plant growing in the hydroponic nutrient 
solution with added arsenite-As at a dose of $1 \mathrm{mg} / \mathrm{L}$ plus Fenton reagent $\left(100 \mu \mathrm{M} \mathrm{H}_{2} \mathrm{O}_{2}\right.$ and $100 \mu \mathrm{M}$ $\mathrm{Fe}^{2+}$ ). For the 1-day experiment, the control and treatment were labelled as $\mathrm{C} 1 \mathrm{~d}$ and $\mathrm{T} 1 \mathrm{~d}$, respectively. For the 30-day experiment, the control and treatment were labelled as C30d and T30d, respectively.

A $500 \mathrm{~mL}$ plastic cup (diameter: $8 \mathrm{~cm}$; height: $15 \mathrm{~cm}$ ) was used as a hydroponic container, which was placed into a black nylon bag to avoid exposure of the plant roots to light. The lid with holes was used to support the plants. Six rice plants were grown in each hydroponic container. The plant growth units were placed randomly in a climate chamber with the daily light-dark cycle being set at $16 \mathrm{~h}: 8 \mathrm{~h}$. The light density during the photoperiod was fixed at $2500 \mathrm{~lx}$. Temperature during the dark and light periods was set at $20{ }^{\circ} \mathrm{C}$ and $28{ }^{\circ} \mathrm{C}$, respectively. Relative humidity was maintained at a range of 80-85\%. All the experiments were performed in 4 replicates.

For the 30-day experiment, the culture solution in each hydroponic container was replenished every 3 days. This included addition of arsenite-As for the control and addition of arsenite-As plus Fenton reagent for the treatment.

At the end of the 1-day experiment, samples of the spent culture solution were taken to determine various As species. For the 30-day experiment, only the first (3 days or 72 hours) spent culture solution was used for analysis of As species. These spent solution samples were labelled as CS1d and TS1d for the control and treatment of the 1-day experiment, respectively, and CS3d and TS3d for the control and the treatment of the first spent solution of the 30-day experiment, respectively.

At the end of each experiment, the plants were harvested for determinations of biomass, various As species in the plant tissues, and $\mathrm{Fe}$ and various As species in the root plaques. Since all the six plants growing in each hydroponic container had very similar growth performance, only three of the 
six plants were randomly selected: (a) the first one was used for determination of the biomass; (b) the second one was used for measurement of As in various plant organs; and (c) the third one was used to extract iron plaque.

\subsubsection{Pot Experiment}

A greenhouse experiment was conducted to observe the growth performance of the rice plants and uptake of As by the rice plants. The experiment lasted for more than 9 months, including two continuous crops with a fallow period of about 3 months. The first crop commenced on September 8 , 2013 and the rice plants were harvested on January 7, 2014; the second crop commenced on April 3, 2014 and the rice plants were harvested on July 22, 2014.

The soil without added As was used as the control $(\mathrm{Ck})$; Treatments 1 and 2 (T1 and T2, respectively) were the artificially contaminated soils without and with added Fenton reagent (100 $\mu \mathrm{M} \mathrm{H}_{2} \mathrm{O}_{2}: 100 \mu \mathrm{M} \mathrm{Fe}^{2+}$ ), respectively. The dose of added arsenite-As in the contaminated soils was set at $50 \mathrm{mg} / \mathrm{kg}$. The thickness of the overlying water layer was maintained at approximately $2 \mathrm{~cm}$. For T2, an appropriate amount of standardized $\mathrm{H}_{2} \mathrm{O}_{2}$ and $\mathrm{FeSO}_{4}$ solution was added to the overlying water to maintain a theoretical concentration of $\mathrm{H}_{2} \mathrm{O}_{2}$ and $\mathrm{Fe}^{2+}$ at $100 \mu \mathrm{M}$ each at the beginning of Fenton reagent addition for each 3-day cycle.

Two seedlings were transplanted to a soil column consisting of alternating layers $(1 \mathrm{~cm}$ thick $)$ of quartz sand and a relevant soil material. This design was to allow easy separation of the root materials from the soils upon harvest. The soil column was contained in a nylon mesh bag (\#400 mesh; diameter: $8 \mathrm{~cm}$; depth: $12 \mathrm{~cm}$ ). Four soil columns were placed in a plastic bucket (Diameter: $22 \mathrm{~cm}$; Height: $15 \mathrm{~cm}$ ) that was filled with the same soil material. This design allowed the separation of rhizospheric soil from the bulk soil by confining the rice plant roots within the nylon mesh bag or so-called rhizo-bag. 
Compound fertilizer (N:P:K=15:15:15) was applied at a rate of $19 \mathrm{~g}$ per pot at the $7^{\text {th }}$ day of the experiment. Additional fertilizers were added at a rate of $6.8 \mathrm{~g} / \mathrm{pot}$ for compound fertilizer and 9.6 $\mathrm{g} / \mathrm{pot}$ for urea in the early tillering stage of the first crop. In the second crop, $6.8 \mathrm{~g} / \mathrm{pot}$ and $7 \mathrm{~g} / \mathrm{pot}$ were added 7 days after transplanting of the rice seedlings and in the heading stage, respectively.

In the first crop, one of the four rhizo-bags (together with the above-ground portion) was randomly removed from each bucket in the heading stage. A second rhizo-bag was removed in the maturity stage. For the second crop, sampling was carried out in the tillering, heading and maturity stages. After collection, the soil materials in each rhizo-bag were recovered by separation from the quartz sands. One of the two rice plants from each rhizo-bag was used for measurement of biomass and another one was used for determination of various As species in the plant tissues.

\subsection{Sample Preparation and Analytical Methods}

For biomass measurements, the straw and root portions of the rice plant were separated. The roots were rinsed with water and the excess moisture on the root surfaces was removed using absorbent paper towels. Fresh biomass of the two portions was obtained before they were oven-dried at $60{ }^{\circ} \mathrm{C}$ until constant weight was attained.

For measurements of various As species in plant tissues, different organs of the rice plant (leaf, stem, root and grain) were deep-frozen at $-40{ }^{\circ} \mathrm{C}$ immediately after collection. The samples were then freeze-dried using a VirTis freeze dryer. The dried plant tissue samples were pulverized (For the rice grains, the hulls were removed but no polish was applied prior to pulverization; for the roots, iron plaque was not removed) and then stored at $-20{ }^{\circ} \mathrm{C}$ before being analyzed. Four As species were determined. These include arsenate-As, arsenite-As, monomethylarsonic acid-As (MMA-As) and dimethylarsinic acid-As (DMA-As). Measurements of various As species were performed using a HPLC-ICP-MS system. For HPLC (Agilent1260) separation, Athena C18-WP column and guard 
column were used. The mobile phase was a mixed solution of citric acid and sodium sulfonate. The flow rate was set at $1.0 \mathrm{~mL} / \mathrm{min}$ with an injection volume of $20 \mu \mathrm{L}$. For ICP-MS (Agilent 7700), argon was used as carrier gas and make-up gas. Details on the instrumental operating conditions are given in Supplementary Table S1.

Iron plaque attached on the root surface was extracted by dithionite-citrate-bicarbnate (DCB, Liu et al., 2005). Briefly, fresh roots were rinsed with deionized water and then dried with adsorbent paper towels. For each rhizo-bag, an appropriate amount of root materials were randomly taken and placed in a beaker containing $30 \mathrm{~mL}$ of mixed solution of $0.03 \mathrm{M} \mathrm{Na}_{3} \mathrm{C}_{6} \mathrm{H}_{5} \mathrm{O}_{7} \cdot 2 \mathrm{H}_{2} \mathrm{O}$ and $0.125 \mathrm{M}$ $\mathrm{NaHCO}_{3} .1 \mathrm{~g}$ of $\mathrm{Na}_{2} \mathrm{~S}_{2} \mathrm{O}_{4}$ was then added into the beaker. After mixing, the beaker with its content was allowed to stand for $30 \mathrm{~min}$. The root materials were removed from the beaker and washed with deionized water three times. The extract, together with the spent washing water, was transferred into a $100 \mathrm{~mL}$ volumetric flask, followed by adding an appropriate amount of water to the mark. The washed roots were then oven-dried at $70^{\circ} \mathrm{C}$ to constant weight.

The iron in the DCB extract was determined by atomic absorption spectrometry (ZEEnit $700 \mathrm{P}$ ). Measurements of various As species in the DCB extract were performed using a HPLC-ICP-MS system. The total As in the root plaque was estimated by the sum of various As species.

\subsection{QC/QA and statistical analysis}

The hydroponic culture experiment was performed in 4 replicates and the pot experiment was performed in 3 replicates. The recovery rates of matrix spike for plant tissue samples in the hydroponic experiment were $80.7 \pm 3.51$ for arsenate-As, $92.5 \pm 2.41$ for arsenite-As, $82.2 \pm 2.72$ for MMA-As and 123 \pm 5.98 for DMA-As. The recovery rates of matrix spike for plant tissue samples in the pot experiment were $89.6 \pm 3.43$ for arsenate-As, $105 \pm 3.44$ for arsenite-As, $106 \pm 3.18$ for MMAAs and 122 \pm 6.96 for DMA-As. Statistical difference analysis was performed using One-way 


\begin{abstract}
ANOVA (SPSS17.0).
\end{abstract}

\title{
$3 \quad$ RESULTS
}

\subsection{Hydroponic Culture Experiment}

For both CS1d and CS3d, the concentration of the originally added arsenite-As more or less remained unchanged (Fig. 1). However, for TS1d and TS3d, all the originally added arsenite-As disappeared and arsenate-As was the only As species detected. The concentration of $\mathrm{As}^{5+}$ in the solution was lower than that of arsenite-As originally added into the system. In particular, TS3d only contained about $3.8 \%$ of the originally added As. Iron precipitates were observed to occur on the bottom and wall of the hydroponic containers.

The fresh biomass (either total, shoot or root) of the rice plant was significantly $(p<0.05)$ higher in the treatment than in the control for both the 1-day and the 30-day experiments though for the dry biomass, the difference between the control and the treatment was statistically insignificant for the 1-day experiment (Table 1).

Arsenate-As dominated the As species, followed by arsenite-As. Very small amounts of methylated As species were also detected (Table 1). There was a consistent trend showing that the arsenate-As and DMA-As in the root portion was significantly $(p<0.05)$ higher in the control than in the treatment for both the 1-day experiment and the 30-day experiment while there was no significant difference $(p>0.05)$ in arsenite-As and MMA-As between the control and the treatment for both the 1-day experiment and the 30-day experiment. Overall, the sum of various As species was higher in the control than in the treatment, especially for the leaf portion.

For the stem portion, mixed results were observed. The 1-day experiment showed a higher sum of As species in the control than in the treatment (Table 1). However, the opposite was observed for 
the 30-day experiment. Unlike root portion, arsenite-As dominated As species in the stem portion and methylated As species was detected only in the 1-day experiment. There was no significant $(p>0.05)$ difference in any As specie between the control and the treatment for both the 1-day experiment and the 30-day experiment.

For the leaf portion, there was no significant $(p>0.05)$ difference in any As species between the control and the treatment except for arsenite-As in the 30-day experiment, which showed a significantly $(p<0.05)$ higher value of arsenite-As in the control than in the treatment (Table 1$)$. Similar to the stem portion, arsenite-As dominated As species and no methylated As species were detected in the treatment for the 30-day experiment.

For both the 1-day and 30-day experiments, the total Fe in the root plaque was greater in the treatment than in the control (Table 1). Total As in the root plaque was significantly greater in the treatment than in the control for the 30-day experiment. However, the same was not observed for the 1-day experiment; there was no significant difference in root plaque-borne As between the control and the treatment.

\subsection{Pot Experiment}

As expected, biomass tended to be smaller in the contaminated soils (T1 and T2) than in the control ( $\mathrm{Ck}$, non-contaminated soil) due to As toxicity (Table 2). Comparison shows that treatment of the contaminated soil with Fenton reagent $(\mathrm{T} 2)$ resulted in a significant $(p<0.05)$ increase in biomass, as compared to $\mathrm{T} 1$ for the first crop and the tillering stage of the second crop. For the maturity stage of the first crop, the growth performance was even better in $\mathrm{T} 2$ than in Ck. However, it is interesting to note that there was no significant difference in dry biomass of the shoot portion between $\mathrm{T} 1$ and $\mathrm{T} 2$ for the heading stage of the second crop and the dry biomass of the shoot portion was even greater in $\mathrm{T} 1$ than in $\mathrm{T} 2$ for the maturity stage of the second crop. For the root portion, 
there was no significant difference in the dry biomass among Ck, T1 and T2. In consistent with the biomass, grain yield also tended to be in the following decreasing order: Ck $(10.6 \mathrm{~g})>\mathrm{T} 2(8.0 \mathrm{~g})>$ T1 (5.7 g).

The sum of various As species in the root portion was greater in $\mathrm{T} 1 \mathrm{than}$ in $\mathrm{Ck}$, particularly in the first crop and the tillering stage of the second crop. By comparison, the root-borne As was significantly $(p<0.05)$ less in $\mathrm{T} 2$ than in $\mathrm{T} 1$ for the heading stage of the first crop and the tillering stage of the second crop. However, no significant $(p>0.05)$ difference in root-borne As between T1 and T2 was observed for the other sampling occasions (Table 3).

Methylated As species only accounted for a small proportion of the root-borne As (Table 3). In most of situations, arsenite-As dominated As species except in $\mathrm{T} 1$ for the heading stage of the first crop and in T1 and T2 for the tillering stage of the second crop when the amount of arsenate-As was close to that of arsenite-As or even slightly greater. One thing in common was that root-borne As tended to be lower in the maturity stage than in the respective earlier growing stages for either arsenite-As or arsenate-As. By comparison, root-borne As at the same growth stage tended to be higher in the first crop than in the second crop for the control and the treatments.

In comparison with the root-borne As, the concentration of As in the stem portion was relatively smaller (Table 4). Like root-borne As, stem-borne As (sum of various As species) also showed a significantly higher value in $\mathrm{T} 1$ than in $\mathrm{Ck}$ for any of the growth stages for the two crops. Unlike the root-borne As, stem-borne As was smaller in T1 than in T2 for the heading stage of the first crop and the tillering stage of the second crop while the opposite was observed for the other three sampling occasions.

The proportion of methylated As species in the sum of As species was generally small except for those in the maturity stage of the first crop (Table 4). For the first crop and the tillering stage of 
the second crop, arsenate-As was greater than did arsenate-As while the opposite was observed for the heading stage and maturity stage of the second crop.

Like the root and stem portions, leaf-borne As (sum of the As species) was consistently greater (significantly at $p<0.05$ ) in $\mathrm{T} 1$ than in $\mathrm{Ck}$ though the difference was not statistically significant in the maturity stage of the second crop (Table 5). For all of the five sampling occasions, there was no significant difference in leaf-borne As between T1 and T2. Like the root and stem portions, methylated As species only took up a small proportion in the sum of various As species. There was a clear trend showing that arsenite-As dominated As species in the heading and maturity stages of the second crop. However, mixed results were observed for other sampling occasions.

The abundance of grain-borne As (sum of various As species) in both the first and second crops had the same pattern: $\mathrm{T} 1>\mathrm{T} 2>\mathrm{Ck}$. This was consistent with the pattern observed for the stem portion in the maturity stage (Fig. 2). By comparison, the concentration of As in the grain portion was consistently higher in the second crop than in the first crop. This was accompanied by the same trend for the stem-borne As. Arsenite-As and DMA-As were the two dominant species. Depending on individual treatments, $\mathrm{Ck}$ had more DMA-As; T2 contained more arsenite-As; and T1 tended to have equal amounts of arsenite-As and DMA-As.

There were orange-colored coating materials (root plaque) on the surfaces of plant roots. However, root coatings did not cover the entire root surface with $\mathrm{T} 1$ tending to have a lower coverage of root plaque, as compared to T2. The abundance of root plaque-borne Fe, as measured by the amount of Fe attached to the surface of per unit of root biomass $(\mathrm{g} / \mathrm{kg})$ in the different stages of rice plant growth for the control and the two treatments is shown in Table 6 . The root plaque-borne Fe tended to be higher in $\mathrm{T} 2$ than in either $\mathrm{T} 1$ or $\mathrm{Ck}$ (significant at $p<0.05$ ). There was a clear trend showing that root plaque-borne As increased from $\mathrm{Ck}$ to $\mathrm{T} 1$ to $\mathrm{T} 2$ for all the five sampling occasions. 


\section{DISCUSSION}

The results obtained from the hydroponic experiment suggest that, under the set experimental conditions, $\mathrm{As}^{3+}$ was resistant to oxidation in the presence of molecular oxygen only. However, addition of Fenton reagent markedly accelerated the oxidation of $\mathrm{As}^{3+}$, resulting in formation of $\mathrm{As}^{5+}$. The decrease in As concentration in the culture solutions suggests that immobilization of As took place. The presence of iron precipitates on the bottom and wall of the hydroponic containers suggests that the $\mathrm{Fe}^{3+}$ formed from Fenton reaction acted as a scavenger to sequester As from the hydroponic solution, resulting in a decrease in solution-borne As. Since the hydroponic nutrient solution contained FeII-EDTA, which is not stable in the presence of oxygen, the Fe from this source could be oxidized to $\mathrm{Fe}^{3+}$, resulting in the formation of iron oxyhydroxide that might add to the plaque (Seibig and and van Eldik, 1997). This was also likely to enhance the local oxidation of $\mathrm{As}^{3+}$ to $\mathrm{As}^{5+}$ (Hug and Leupin, 2003). In addition, the As(III)-oxidizing microbes could also play an important role in oxidizing As on the root iron plaque (Hu et al. 2015).

The generally lower concentration of As in the rice plant tissue in the treatment, relative to the control, can be attributed to the reduced availability of As in the hydroponic solution. The predominant presence of arsenate-As in the root portion appears to suggest that while both arsenate and arsenite might be taken up by the rice seedlings, the uptake of As by root took place more favourably through an arsenate pathway. The change in the predominant As species from arsenateAs to arsenite-As in the above-ground portion reflects the in-plant reduction of arsenate-As (Kramar et al., 2015).

The significantly greater root plaque-borne Fe concentration in the treatment than in the control suggests that addition of Fenton reagent significantly enhanced the formation of iron compounds on 
the root surfaces of the rice plants. Liu et al. (2006) suggested that root plaque-Fe was in mineral forms of iron oxyhydroxides. This work demonstrates that addition of Fenton reagent enhanced the formation of $\mathrm{Fe}^{3+}$-containing chemical compounds on the root surface.

Although no significant difference between the control and the treatment was observed for the 1day experiment, the root plaque-borne As was significantly $(p<0.05)$ greater in the treatment than in the control for the 30-day experiment. This suggests that the addition of Fenton reagent could enhance retention of As by the root plaque. However it took time to incorporate solution-borne As into root plaque and a duration of 24 hours was not sufficient to allow this to take place even when Fenton reagent was added into the system. For the control, transformation of arsenite-As to arsenateAs did not take place and arsenite was the only form of arsenic in the nutrient solution (Fig. 1). Therefore, any arsenate contained in the root plaque was likely to be formed as a result of arsenite oxidation driven by root-released oxygen. For the treatment, production of arsenate was markedly enhanced due to Fenton reaction. From Fig. 1, it is clear that conversion of all arsenite-As into arsenate-As was completed within 1 day after addition of Fenton reagent. The arsenate formed was then gradually removed from the nutrient solution by deposition as iron precipitates and plant uptake.

In the pot experiment, the poorer growth performance, as indicated by smaller biomass in $\mathrm{T} 1 \mathrm{than}$ in Ck during the first crop and the tillering stage of the second crop suggests that an initial dose of As at $50 \mathrm{mg} / \mathrm{kg}$ was sufficient to cause phytotoxicity to the rice plants under the set experimental conditions. Das et al. (2013) observed phytotoxicity to paddy rice at a dose of $40 \mathrm{mg} \mathrm{As} / \mathrm{kg}$, which is very similar to $50 \mathrm{mg} \mathrm{As} / \mathrm{kg}$ in this experiment. The toxic effects of As on rice plant growth became less significant during the heading and maturity stages of the second crop. This may be attributed to reduced bioavailability of the added As due to As immobilization through formation of practically insoluble minerals such as scorodite or adsorption by soil colloids such as Fe oxyhydroxides (Lin and Puls, 2000; Campbell and Nordstrom, 2014; Serrano et al., 2015). Contamination of the soils by 
As led to increased uptake of As by the plants, which impedes the physiological functions of the plants (Hughes, 2002; Islam et al., 2015). However, the application of Fenton reagent effectively reduced this harmful effect and significantly enhanced the growth of the rice plants grown in the Ascontaminated soils. It is interesting to note that the significant increase in biomass in the first crop and the tillering stage of the second crop in T2, as compared to T1, was accompanied by a significant reduction in root-borne As in T2, relative to T1 while the insignificant difference in biomass between $\mathrm{T} 1$ and $\mathrm{T} 2$ in the heading and maturity stages of the second crop was consistent with the insignificant difference in root-borne As between $\mathrm{T} 1$ and $\mathrm{T} 2$. It is noted that the biomass tended to be greater in the first crop than in the second crop (Table 2). The rice cultivar (TY122) used for the experiment was the one that is more suitable for being grown during the period from autumn to early winter (the first crop) than during the period from late spring to summer (the second crop). In addition, the application rate of chemical fertilizers was relatively lower in the second crop than in the first crop, and this might also affect the growth performance of the rice plants in the second crop.

The relatively low level of root plaque-borne As in $\mathrm{Ck}$ reflected the limited availability of As in the non-contaminated soil. A significantly higher level of root plaque-borne As in T2, as compared to $\mathrm{T} 1$ is attributable to the enhanced formation of iron plaques on the root surfaces of the rice plants due to application of Fenton reagent, which in turn allowed more As being intercepted when As in the soil solution moved towards the surfaces of the plant roots, and consequently reduced the amounts of As being taken by the plant roots.

The trend that $\mathrm{As}_{\text {Stem }} / \mathrm{As}_{\text {Root }}$ and $\mathrm{As}_{\text {leaf }} / \mathrm{As}_{\text {Root }}$ increased over time (Table 7 and Table 8) suggests that the root-to-shoot translocation of As was enhanced as the rice plants became more mature, possibly due to intensified transpiration. The much higher $\mathrm{As}_{\mathrm{Stem}} / \mathrm{As}_{\mathrm{Root}}$ at the maturity stage in the second crop than in the first crop indicates that the efficiency of root-to-stem As translocation was improved due to the reduced As phytotoxicity, which allowed better growth performance of the rice 
plants being achieved. This explains the much higher rice grain-borne As in the second crop than in the first crop.

The capacity of root plaque to impede As flux towards the root surfaces in T1 were limited, leading to substantial uptake of As by the roots. This could also be due to that younger roots and the younger parts of the old roots that play key role in plant uptake of nutrients and metals were hardly coated by iron plaque, as also pointed out by other workers (Seyfferth et al., 2010; Yamaguchi et al., 2014). The addition of Fenton reagent led to production of $\mathrm{Fe}^{3+}$ and hydroxyl radical that enhanced formation of iron precipitates and $\mathrm{As}^{3+}-\mathrm{As}^{5+}$ conversion. This effect was not limited to rhizosphere but also the bulk soils. As demonstrated in the hydroponic experiment, solution-borne arsenite can be oxidized and removed from the culture solution within a relatively short period of time after addition of Fenton reagent. It is therefore likely that arsenite in the soil pore water could experience the same process for the pot experiment. The immobilization of As in the bulk soil could markedly reduce the supply of dissolved As for the plant root, leading to reduced uptake of As by the rice plants. The effect of $\mathrm{FeSO}_{4}$ addition on enhancing formation of iron plaque on rice root surfaces was previously observed by Hossain et al. (2009)

The concentration of As $\left(0.26 \mathrm{mg} / \mathrm{kg}\right.$ for the $1^{\text {st }} \mathrm{crop}$ and $0.55 \mathrm{mg} / \mathrm{kg}$ for the $2^{\text {nd }}$ crop $)$ in the grain of rice plants grown in the contaminated soils (T1) far exceeded the maximum limit of 0.1 $\mathrm{mg} / \mathrm{kg}$ set by the European Union for the rice destined for the production of foods for infants and young children (Signes-Pastor et al. 2017) though the level of As could be lower than these values if the rice grains are polished (Meharg et al., 2008). The significant reduction in rice grain-borne As in both the first and second crops due to addition of Fenton reagent sheds some light on the possible role of rainwater-borne $\mathrm{H}_{2} \mathrm{O}_{2}$ in alleviating As contamination in rice grain. In our recent experiment examining the paddy soils receiving natural rainwater containing hydrogen peroxide, a similar effect like what was showed in this microcosm experiment was observed, suggesting that rainwater-borne 
hydrogen peroxide does affect arsenic chemistry in paddy soils (unpublished data). This raises a question on whether rice produced from areas receiving abundant rainfall tends to contain less arsenic. It will be interesting to establish whether there is a relationship between annual rainfall and rice grain-borne As on a global scale.

From a mitigation perspective, the research findings have implications for developing costeffective management strategies and remediation techniques to reduce As uptake by rice plants and accumulation in the rice grain. The uses of industrial grade $\mathrm{H}_{2} \mathrm{O}_{2}$ (US\$500/t, source: Zhengzhou Huize Biochemical Technology Co., Ltd) and $\mathrm{FeSO}_{4}$ (US\$100/t, source: Dalian Future International Co., Ltd.) are not economically prohibitive. A rough calculation based on the experimental design in this study gives an estimated cost of US\$89 per hectare for the purchase of the required chemicals. If appropriate procedure for mixing the Fenton reagent into the irrigation water can be developed, significant reduction of As level in rice grain may be achieved cost-effectively in rice-producing areas where the soils contain high level of As or where As-bearing groundwater is used for irrigation purpose.

\section{Acknowledgements}

This work was partly supported by the research grants from the Natural Science Foundation of China (Project No. 41271469) and under the National High and New Technology Programs (863) of China (Project No. 2013AA102402).

\section{References}

Armstrong, W., 1964. Oxygen diffusion from the roots of some British bog plants. Nature. 204, 801802.

Becker, M., Asch, F., 2005. Iron toxicity in rice conditions and management concepts. J. Plant. Nutr. Soil Sci. 168, 558-573.

Campbell, K.M., Nordstrom, D.K., 2014. Arsenic speciation and sorption in natural environments. 
Chen, Z., Zhu, Y.G., Liu, W.J., Meharg, A.A., 2005. Direct evidence showing the effect of root surface iron plaque on arsenite and arsenate uptake into rice (Oryza sativa) roots. New. Phytol. $165,91-97$.

Clemens, S., Ma, J.F., 2016. Toxic heavy metal and arsenic accumulation in crop plants and foods. Annu. Rev. Plant. Biol. 67, 12.1-12.24.

Cooper, W.J, Zika, R.G., Petasne, R.G., Plane, J. M.C., 1988. Photochemical formation of $\mathrm{H}_{2} \mathrm{O}_{2}$ natural waters exposed to sunlight. Environ. Sci. Technol. 22, 1156-1160.

Das, I., Ghosh, K., Das, D.K., Sanyal, S.K., 2013. Assessment of arsenic toxicity in rice plants in areas of West Bengal. Chem. Spec. Bioavailab. 25(3), 201-208.

Gonçalves, C., Dos Santos, M.A., Fornaroc, A., Pedrotti, J.J., 2010. Hydrogen peroxide in the rainwater of Sao Paulo megacity: measurements and controlling factors. J. Braz. Chem. Soc. 21, 331-339.

Guo, J., Tilgner, A., Yeung, C., Wang, Z., Louie, P.K.K., Luk, C.W.Y., Xu, Z., Yuan, C., Gao, Y., Poon, S., Herrmann, H., Lee, S., Lam, K.S., Wang, T., 2014. Atmospheric peroxides in a polluted subtropical environment: seasonal variation, sources and sinks, and importance of heterogeneous processes. Environ. Sci. Technol. 48, 1443-1450.

Hu, M., Li, F.B., Liu, C.P., Wu, W.J., 2015. The diversity and abundance of As(III) oxidizers on root iron plaque is critical for arsenic bioavailability to rice. Sci. Rep. 5, 13611.

Hug, S.J., Leupin, O., 2003. Iron-catalyzed oxidation of arsenic(III) by oxygen and by hydrogen peroxide: pH-dependent formation of oxidants in the Fenton reaction. Environ. Sci. Technol. 37, 2734-2742.

Hughes, M.F., 2002. Arsenic toxicity and potential mechanisms of action. Toxicol. Lett. 133, 1-16.

Hossain, M.B., Jahiruddin, M., Loeppert, R. H., Panaullah, G.M., Islam, M.R., Duxbury, J.M., 2009. The effects of iron plaque and phosphorus on yield and arsenic accumulation in rice. Plant. Soil. $317,167-176$.

Islam, E., Khan, M.T., Irem, S., 2015. Biochemical mechanisms of signaling: Perspectives in plants under arsenic stress. Ecotox. Environ. Safe. 114, 126-133.

Kramar, U., Norra, S., Berner, Z., Kiczka, M., Chandrasekharam, D., 2015. On the distribution and speciation of arsenic in the soil-plant-system of a rice field in West-Bengal, India: A $\mu$ synchrotron techniques based case study. Appl. Geochem. Available online, 1-11.

Kögel-Knabner, I., Amelung, W., Cao, Z., Fiedler, S., Frenzel, P., Jahn, R., Kalbitz, K., Kölbl, A., Schloter, M., 2010. Biogeochemistry of paddy soils. Geoderma. 157, 1-14.

Lee, C.H., Hsieh, Y.C., Lin, T.H., Lee, D.Y., 2013. Iron plaque formation and its effect on arsenic 
Li, R.Y., Stroud, J.L., Ma, J.F., Mcgrath, S.P., Zhao, F.J., 2009. Mitigation of arsenic accumulation in rice with water management and silicon fertilization. Environ. Sci. Technol. 43, 3778-3783.

Lin, Z., Puls, R.W., 2000. Adsorption, desorption, and oxidation of arsenic affected by clay minerals and aging process. Environ. Geol. 39, 753-759.

Liu, W.J., Zhu, Y.G., Hu, Y., Williams, P.N., Gault, A.G., Meharg, A.A., Charnock, J.M., Smith, F.A., 2006. Arsenic sequestration in iron plaque, its accumulation and speciation in mature rice plants (Oryza Sativa L.). Environ. Sci. Technol. 40, 5730-5736.

Liu, W.J., Zhu, Y.G., Smith, F.A., 2005. Effects of iron and manganese plaques on arsenic uptake by rice seedlings (Oryza sativa L.) grown in solution culture supplied with arsenate and arsenite. Plant. Soil. 227, 127-138.

Meharg, A.A., 2004. Arsenic in rice-understanding a new disaster for South-East Asia. Trends. Plant. Sci. 9, 415-417.

Meharg, A.A., Lombi, E., Williams, P.N., Scheckel, K.G., Feldmann, J., Raab, A., Zhu, Y., Islam, R., 2008. Speciation and localization of arsenic in white and brown rice grains. Environ Sci Technol. 42(4), 1051-1057.

Schoof, R.A., Yost, L.J., Eickhoff, J., Crecelius, E.A., Cragin, D.W., Meacher, D.M., Menzel D.B., 1999. A market basket survey of inorganic arsenic in food. Food. Chem. Toxicol. 37, 839-846.

Serrano, S., Gomez-Gonzalez, M.A., O’Day, P.A., Laborda, F., Bolea, E., Garrido, F., 2015. Arsenic speciation in the dispersible colloidal fraction of soils from a mine-impacted creek. J. Hazard. Mater. 286, 30-40.

Seibig, S., van Eldik, R., 1997. Kinetics of [FeII(edta)] oxidation by molecular oxygen revisited. New evidence for a multistep mechanism. Inorg. Chem. 36, 4115-4120.

Seyfferth, A.L., Webb, S.M., Andrews, J.C., Fendorf, S., 2010. Arsenic localization, speciation, and Co-occurrence with iron on rice (Oryza sativa L.) roots having variable Fe coatings. Environ. Sci. Technol. 44, 8108-8113.

Signes-Pastor A.J., Woodside, J.V., McMullan, P., Mullan, K., Carey, M., Karagas, M.R., Meharg, A.A., 2017. Levels of infants' urinary arsenic metabolites related to formula feeding and weaning with rice products exceeding the EU inorganic arsenic standard. PLoS ONE 12(5), e0176923. https://doi.org/10.1371/journal.pone.0176923

Sinha, B., Bhattacharyya, K., 2015. Arsenic toxicity in rice with special reference to speciation in Indian grain and its implication on human health. J. Sci. Food. Agr. 95, 1435-1444.

Somenahally, A.C., Hollister, E.B., Yan, W.G., Gentry, T.J., Loeppert, R.H., 2011. Water management impacts on arsenic speciation and iron-reducing bacteria in contrasting rice- 
Spanu, A., Daga, L., Orlandoni, A.M., Sanna, G., 2012. The role of irrigation techniques in arsenic bioaccumulation in rice (Oryza sativa L.). Environ. Sci. Technol. 46, 8333-8340.

Su, Y.H., McGrath, S., Zhao, F.J., 2010. Rice is more efficient in arsenite uptake and translocation than wheat and barley. Plant. Soil. 328, 27-34.

Syu, C.H., Huang, C.C., Jiang, P.Y., Lee, C.H., Lee, D.Y., 2015. Arsenic accumulation and speciation in rice grains influenced by arsenic phytotoxicity and rice genotypes grown in arsenic-elevated paddy soils. J. Hazard. Mater. 286, 179-186.

Syu, C.H., Jiang, P.Y., Huang, H.H., Chen, W.T., Lin, T.H., Lee, D.Y., 2013. Arsenic sequestration in iron plaque and its effect on As uptake by rice plants grown in paddy soils with high contents of As, iron oxides, and organic matter. Soil. Sci. Plant. Nutr. 59, 463-471.

Wang, X., Peng, B., Tan, C.Y., Ma, L., Rathinasabapathi, B., 2015. Recent advances in arsenic bioavailability, transport, and speciation in rice. Environ. Sci. Pollut. Res. 22, 5742-5750.

Willey, J.D., Kieber, R.J., Lancaster, R.D., 1996. Coastal rainwater hydrogen peroxide: concentration and deposition. J. Autom. Chem. 25, 149-165.

Williams, P.N., Islam, M.R., Adomako E.E., Raab, A., Hossain, S.A., Zhu, Y.G., Feldmann, J., Meharg, A.A., 2006. Increase in rice grain arsenic for regions of Bangladesh irrigating paddies with elevated arsenic in groundwaters. Environ. Sci. Technol. 40, 4903-4908.

Williams, P.N., Villada, A., Deacon, C., Raab, A., Figuerola, J., Green, A.J., Feldmann, J., Meharg, A.A., 2007. Greatly enhanced arsenic shoot assimilation in rice leads to elevated grain levels compared to wheat and barley. Environ. Sci. Technol. 41, 6854-6859.

Xu, X.Y., Mcgrath, S.P., Meharg, A.A., Zhao, F.J., 2008. Growing rice aerobically markedly decreases arsenic accumulation. Environ. Sci. Technol. 42, 5574-5579.

Yamaguchi, N., Ohkura, T., Takahashi, Y., Maejima, Y., Arao, T., 2014. Arsenic distribution and speciation near rice roots influenced by iron plaques and redox conditions of the soil matrix. Environ. Sci. Technol. 48, 1549-1556.

Zhao, F.J., Ma, J.F., Meharg, A.A., McGrath, S.P., 2009. Arsenic uptake and metabolism in plants. New. Phytol. 181, 777-794.

Zhao, F.J., McGrath, S.P., Meharg, A.A., 2010. Contaminant: mechanisms of plant uptake and metabolism and mitigation strategies, Annu. Rev. Plant. Biol. 61, 535-59.

Zhu, Y.G., Williams, P.N., Meharg, A.A., 2008. Exposure to inorganic arsenic from rice: A global health issue? Environ. Pollut. 154, 169-171.

Zhu, Y.G., Yoshinaga, M., Zhao, F.J. Rosen, B.P., 2014. Earth abides arsenic biotransformations. Annu. Rev. Earth. Planet. Sci. 42, 443-67 


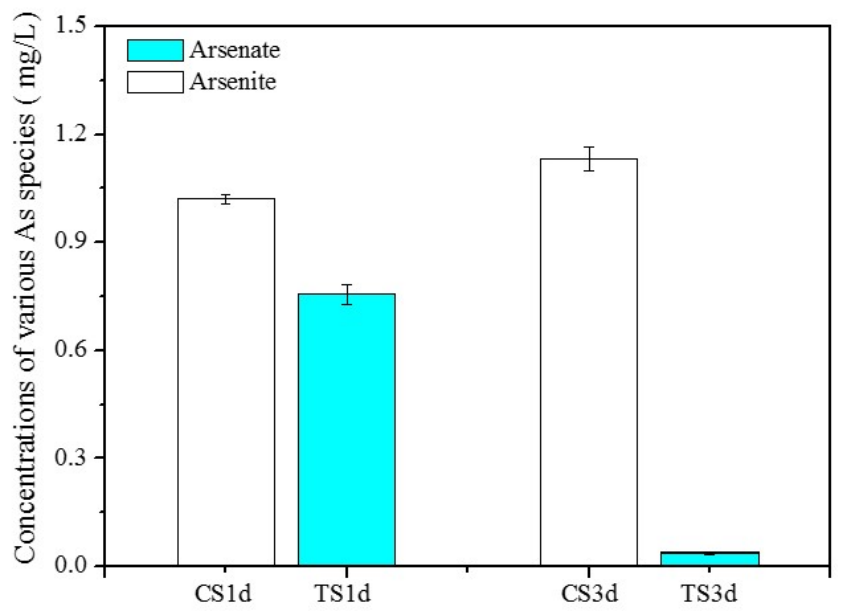

Fig 1 Concentration of various arsenic species in the culture solution in the control (CS) and the treatment (TS) at the end of the 1-day experiment $(24 \mathrm{~h})$ and at the end of the first nutrient replenishment cycle $(\mathbf{7 2} \mathbf{h})$ of the 30-day experiment. All values are presented as mean \pm standard error $(n=4)$. 


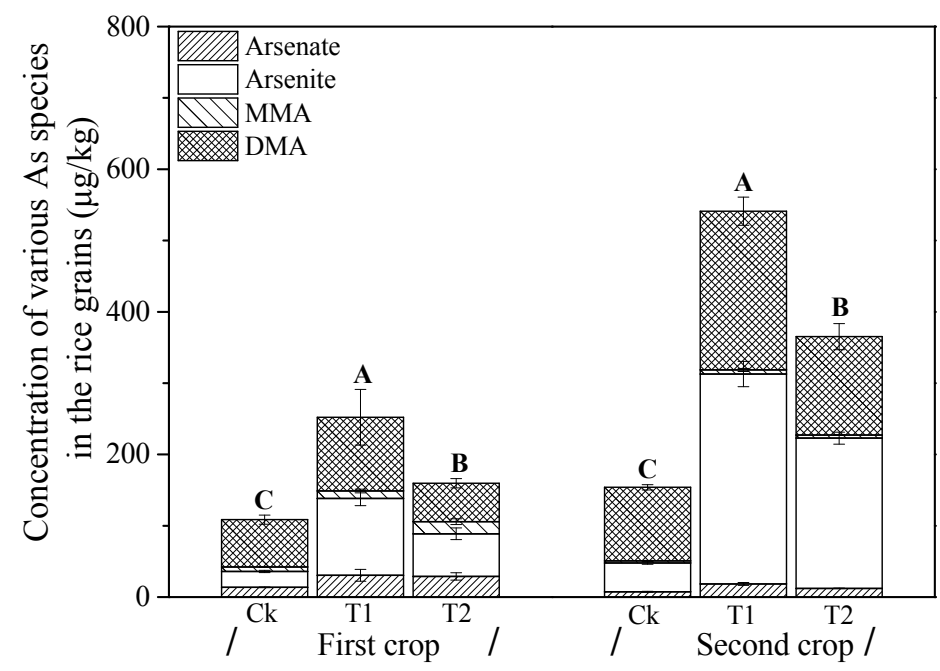

Fig 2 Concentration of various arsenic species in the rice grain harvested in the first crop and second crop for the control (CK) and the two treatments (T1 and T2) in the pot experiment. All values are presented as mean \pm standard error $(n=3)$ and bars with different letters indicate significantly $(P<0.05)$ different means for the sum of various arsenic species (arsenate-As, arseniteAs, MMA-As and DMA-As). 
Table 1 Dry biomass, arsenic species in plant tissues, and iron and arsenic species in root plaque for the 1-day and 30-day hydroponic experiments

\begin{tabular}{llcccc}
\hline & & $\mathrm{C} 1 \mathrm{~d}$ & $\mathrm{~T} 1 \mathrm{~d}$ & $\mathrm{C} 30 \mathrm{~d}$ & $\mathrm{~T} 30 \mathrm{~d}$ \\
\hline Dry biomass $(\mathrm{g})$ & Straw & $0.20 \pm 0.01$ & $0.26 \pm 0.05$ & $0.56 \pm 0.05$ & $0.78 \pm 0.06$ \\
& Root & $0.07 \pm 0.01$ & $0.06 \pm 0.00$ & $0.23 \pm 0.06$ & $0.30 \pm 0.02$ \\
As (root portion, $\mathrm{mg} / \mathrm{kg})$ & Arsenate-As & $98.5 \pm 3.04^{*}$ & $70.0 \pm 1.85$ & $315 \pm 9.74^{*}$ & $238 \pm 6.30$ \\
& Arsenite-As & $18.4 \pm 0.63$ & $18.7 \pm 3.02$ & $59.0 \pm 2.03$ & $59.9 \pm 9.67$ \\
& MMA-As & $2.08 \pm 0.44$ & $0.82 \pm 0.10$ & $4.99 \pm 1.06$ & $1.96 \pm 0.24$ \\
& DMA-As & $3.40 \pm 0.78^{*}$ & $1.65 \pm 0.15$ & $8.84 \pm 2.04^{*}$ & $4.29 \pm 0.38$ \\
& Total As & 122 & 91.1 & 387 & 304 \\
As (stem portion, mg/kg) & Arsenate-As & $5.14 \pm 0.61$ & $4.42 \pm 0.68$ & $15.9 \pm 0.21$ & $19.5 \pm 1.49$ \\
& Arsenite-As & $11.4 \pm 0.73$ & $8.86 \pm 0.63$ & $22.5 \pm 1.70$ & $25.7 \pm 3.29$ \\
& MMA-As & $\mathrm{ND}$ & $\mathrm{ND}$ & $\mathrm{ND}$ & $\mathrm{ND}$ \\
& DMA-As & $1.1 \pm 0.12$ & $0.64 \pm 0.31$ & $\mathrm{ND}$ & $\mathrm{ND}$ \\
& Total As & 17.6 & 13.9 & 38.4 & 45.2 \\
As (leaf portion, $\mathrm{mg} / \mathrm{kg})$ & Arsenate-As & $1.85 \pm 0.38$ & $2.04 \pm 0.26$ & $20.6 \pm 2.56$ & $11.3 \pm 1.47$ \\
& Arsenite-As & $3.13 \pm 0.37$ & $3.48 \pm 0.12$ & $45.7 \pm 6.11^{*}$ & $27.6 \pm 2.69$ \\
& MMA-As & $\mathrm{ND}$ & $\mathrm{ND}$ & $\mathrm{ND}$ & $\mathrm{ND}$ \\
& DMA-As & $0.14 \pm 0.02$ & $0.06 \pm 0.02$ & $\mathrm{ND}$ & $\mathrm{ND}$ \\
& Total As & 5.12 & 5.58 & 66.3 & 38.9 \\
& Total Fe & $5.86 \pm 1.38^{*}$ & $8.29 \pm 0.46$ & $2.00 \pm 0.18^{*}$ & $8.45 \pm 0.58$ \\
Root plaque-Fe $(\mathrm{g} / \mathrm{kg})$ & Total As & $60.9 \pm 1.26$ & $56.2 \pm 1.12$ & $76.6 \pm 0.51^{*}$ & $115 \pm 5.59$ \\
\hline
\end{tabular}

All values are presented as mean \pm standard error $(n=4)$. Independent sample t-test was used to determine whether the two mean values obtained for the control and the treatment differ significantly. Pairs marked with an asterisk indicate significant $(\mathrm{P}<0.05)$ difference between the control and the treatment for each harvest time. ND: not detectable. 
Table 2 Fresh and dry weight (g) of the shoot and root in the first crop and second crop for the control and the two treatments for the pot experiment

\begin{tabular}{llllll}
\hline Growth stage & Treatments & $\begin{array}{c}\text { Shoot } \\
\text { fresh weight }\end{array}$ & $\begin{array}{c}\text { Shoot } \\
\text { dry weight }\end{array}$ & $\begin{array}{c}\text { Root } \\
\text { fresh weight }\end{array}$ & $\begin{array}{c}\text { Root } \\
\text { dry weight }\end{array}$ \\
\hline Heading & $\mathrm{Ck}$ & $47.4 \pm 1.11 \mathrm{a}$ & $8.88 \pm 0.59 \mathrm{a}$ & $20.5 \pm 1.35 \mathrm{a}$ & $4.48 \pm 0.74 \mathrm{a}$ \\
$\left(1^{\text {st }}\right.$ crop) & $\mathrm{T} 1$ & $14.5 \pm 1.32 \mathrm{c}$ & $2.88 \pm 0.3 \mathrm{c}$ & $6.04 \pm 0.97 \mathrm{c}$ & $0.94 \pm 0.21 \mathrm{c}$ \\
& $\mathrm{T} 2$ & $28.8 \pm 1.84 \mathrm{~b}$ & $6.14 \pm 0.27 \mathrm{~b}$ & $13.9 \pm 0.68 \mathrm{~b}$ & $2.76 \pm 0.24 \mathrm{~b}$ \\
Maturity & $\mathrm{Ck}$ & $29.1 \pm 4.20 \mathrm{ab}$ & $14.7 \pm 1.45 \mathrm{a}$ & $24.0 \pm 0.91 \mathrm{~b}$ & $8.52 \pm 0.91 \mathrm{~b}$ \\
$\left(1^{\text {st }}\right.$ crop) & $\mathrm{T} 1$ & $21.1 \pm 0.45 \mathrm{c}$ & $8.24 \pm 1.05 \mathrm{c}$ & $4.11 \pm 0.29 \mathrm{c}$ & $1.64 \pm 0.32 \mathrm{c}$ \\
& $\mathrm{T} 2$ & $31.0 \pm 1.82 \mathrm{a}$ & $13.2 \pm 0.60 \mathrm{ab}$ & $31.0 \pm 4.21 \mathrm{a}$ & $14.6 \pm 1.32 \mathrm{a}$ \\
Tillering & $\mathrm{Ck}$ & $5.40 \pm 0.58 \mathrm{a}$ & $0.71 \pm 0.11 \mathrm{a}$ & $0.52 \pm 0.05 \mathrm{a}$ & $0.12 \pm 0.02 \mathrm{a}$ \\
$\left(2^{\text {nd }}\right.$ crop$)$ & $\mathrm{T} 1$ & $1.57 \pm 0.13 \mathrm{c}$ & $0.23 \pm 0.02 \mathrm{c}$ & $0.14 \pm 0.00 \mathrm{c}$ & $0.07 \pm 0.02 \mathrm{ab}$ \\
& $\mathrm{T} 2$ & $2.75 \pm 0.53 \mathrm{bc}$ & $0.41 \pm 0.09 \mathrm{bc}$ & $0.30 \pm 0.05 \mathrm{bc}$ & $0.08 \pm 0.01 \mathrm{ab}$ \\
Heading & $\mathrm{Ck}$ & $24.7 \pm 2.72 \mathrm{a}$ & $8.07 \pm 1.23 \mathrm{a}$ & $13.3 \pm 1.70 \mathrm{ab}$ & $1.73 \pm 0.17 \mathrm{a}$ \\
$\left(2^{\text {nd }}\right.$ crop) & $\mathrm{T} 1$ & $18.5 \pm 1.29 \mathrm{ab}$ & $6.52 \pm 0.31 \mathrm{ab}$ & $17.8 \pm 0.80 \mathrm{a}$ & $2.12 \pm 0.11 \mathrm{a}$ \\
& $\mathrm{T} 2$ & $16.8 \pm 2.17 \mathrm{~b}$ & $6.42 \pm 0.76 \mathrm{ab}$ & $18.4 \pm 2.01 \mathrm{a}$ & $2.25 \pm 0.64 \mathrm{a}$ \\
Maturity & $\mathrm{Ck}$ & $15.9 \pm 1.46 \mathrm{a}$ & $6.63 \pm 0.68 \mathrm{ab}$ & $14.0 \pm 1.50 \mathrm{a}$ & $1.77 \pm 0.24 \mathrm{a}$ \\
$\left(2^{\text {nd }}\right.$ crop) & $\mathrm{T} 1$ & $16.7 \pm 1.87 \mathrm{a}$ & $7.27 \pm 0.78 \mathrm{a}$ & $11.8 \pm 2.87 \mathrm{a}$ & $2.43 \pm 0.67 \mathrm{a}$ \\
& $\mathrm{T} 2$ & $12.8 \pm 1.68 \mathrm{ab}$ & $4.74 \pm 0.76 \mathrm{~b}$ & $9.36 \pm 0.58 \mathrm{ab}$ & $1.87 \pm 0.12 \mathrm{a}$ \\
\hline
\end{tabular}

All values are presented as mean \pm standard error $(n=3)$ and means with different letters in the same column for each of the five sampling occasions are significantly different $(p<0.05)$. 
Table 3 Concentration $(\mathrm{mg} / \mathrm{kg}$ ) of various As species in the root portion of the rice plant during different growth stages for the pot experiment

\begin{tabular}{lcccccc}
\hline Growth stage & Treatment & Arsenate-As & Arsenite-As & MMA-As & DMA-As & Sum \\
\hline Heading & Ck & $12.7 \pm 2.10 \mathrm{bc}$ & $19.1 \pm 1.94 \mathrm{c}$ & $1.20 \pm 0.14 \mathrm{a}$ & $0.10 \pm 0.01 \mathrm{c}$ & $33.1 \pm 3.74 \mathrm{~b}$ \\
$\left(1^{\text {st }}\right.$ crop) & $\mathrm{T} 1$ & $73.2 \pm 0.78 \mathrm{a}$ & $60.1 \pm 1.57 \mathrm{a}$ & $1.21 \pm 0.12 \mathrm{a}$ & $1.41 \pm 0.22 \mathrm{a}$ & $136 \pm 2.16 \mathrm{a}$ \\
& $\mathrm{T} 2$ & $11.8 \pm 0.37 \mathrm{c}$ & $32.8 \pm 5.95 \mathrm{~b}$ & $0.65 \pm 0.04 \mathrm{~b}$ & $0.79 \pm 0.11 \mathrm{~b}$ & $46.1 \pm 6.16 \mathrm{~b}$ \\
Maturity & $\mathrm{Ck}$ & $1.21 \pm 0.05 \mathrm{c}$ & $7.04 \pm 1.08 \mathrm{c}$ & $0.79 \pm 0.02 \mathrm{c}$ & $0.89 \pm 0.09 \mathrm{ab}$ & $9.93 \pm 1.10 \mathrm{~b}$ \\
$\left(1^{\text {st }}\right.$ crop) & $\mathrm{T} 1$ & $2.03 \pm 0.31 \mathrm{~b}$ & $30.0 \pm 1.56 \mathrm{a}$ & $1.19 \pm 0.15 \mathrm{~b}$ & $0.60 \pm 0.03 \mathrm{~b}$ & $33.8 \pm 1.11 \mathrm{a}$ \\
& $\mathrm{T} 2$ & $3.82 \pm 0.24 \mathrm{a}$ & $22.1 \pm 2.96 \mathrm{~b}$ & $1.52 \pm 0.10 \mathrm{a}$ & $1.28 \pm 0.23 \mathrm{a}$ & $28.7 \pm 3.38 \mathrm{a}$ \\
& $\mathrm{Ck}$ & $8.56 \pm 0.68 \mathrm{c}$ & $11.1 \pm 1.15 \mathrm{~b}$ & $0.03 \pm 0.01 \mathrm{~b}$ & $0.59 \pm 0.03 \mathrm{~b}$ & $20.3 \pm 1.45 \mathrm{c}$ \\
Tillering & $\mathrm{T} 1$ & $82.6 \pm 4.15 \mathrm{a}$ & $85.9 \pm 2.15 \mathrm{a}$ & $2.90 \pm 0.37 \mathrm{a}$ & $2.51 \pm 0.29 \mathrm{a}$ & $174 \pm 6.72 \mathrm{a}$ \\
$\left(2^{\text {nd }}\right.$ crop) & $\mathrm{T} 2$ & $27.8 \pm 1.27 \mathrm{~b}$ & $18.2 \pm 1.26 \mathrm{~b}$ & $0.17 \pm 0.02 \mathrm{~b}$ & $0.66 \pm 0.04 \mathrm{~b}$ & $46.9 \pm 0.38 \mathrm{~b}$ \\
& $\mathrm{Ck}$ & $3.04 \pm 0.39 \mathrm{~b}$ & $14.6 \pm 0.64 \mathrm{~b}$ & $0.14 \pm 0.00 \mathrm{a}$ & $1.33 \pm 0.23 \mathrm{a}$ & $19.1 \pm 0.53 \mathrm{~b}$ \\
Heading & $\mathrm{T} 1$ & $4.91 \pm 0.64 \mathrm{ab}$ & $49.7 \pm 5.64 \mathrm{a}$ & $0.35 \pm 0.05 \mathrm{a}$ & $0.77 \pm 0.17 \mathrm{a}$ & $55.7 \pm 6.11 \mathrm{a}$ \\
$\left(2^{\text {nd }}\right.$ crop) & $\mathrm{T} 2$ & $6.52 \pm 0.94 \mathrm{a}$ & $52.4 \pm 2.92 \mathrm{a}$ & $0.22 \pm 0.01 \mathrm{a}$ & $1.27 \pm 0.23 \mathrm{a}$ & $60.4 \pm 4.01 \mathrm{a}$ \\
& $\mathrm{Ck}$ & $1.60 \pm 0.21 \mathrm{a}$ & $4.94 \pm 0.32 \mathrm{c}$ & $0.34 \pm 0.04 \mathrm{~b}$ & $0.50 \pm 0.08 \mathrm{~b}$ & $7.38 \pm 0.57 \mathrm{~b}$ \\
Maturity & $\mathrm{T} 1$ & $1.89 \pm 0.55 \mathrm{a}$ & $9.30 \pm 0.69 \mathrm{~b}$ & $1.42 \pm 0.20 \mathrm{a}$ & $0.73 \pm 0.13 \mathrm{ab}$ & $13.3 \pm 1.05 \mathrm{a}$ \\
$\left(2^{\text {nd }}\right.$ crop) & $\mathrm{T} 2$ & $1.61 \pm 0.39 \mathrm{a}$ & $12.4 \pm 1.06 \mathrm{a}$ & $0.82 \pm 0.04 \mathrm{ab}$ & $0.88 \pm 0.05 \mathrm{a}$ & $15.7 \pm 1.43 \mathrm{a}$ \\
&
\end{tabular}

All values are presented as mean \pm standard error $(n=3)$ and means with different letters in the same column for each of the five sampling occasions are significantly different $(p<0.05)$. 
Table 4 Concentration $(\mathrm{mg} / \mathrm{kg})$ of various As species in the stem portion of the rice plant during different growth stages for the pot experiment

\begin{tabular}{|c|c|c|c|c|c|c|}
\hline Growth stage & Treatment & Arsenate & Arsenite & MMA & DMA & Sum \\
\hline Heading & $\mathrm{Ck}$ & $1.40 \pm 0.09 \mathrm{c}$ & $1.02 \pm 0.13 \mathrm{c}$ & $0.19 \pm 0.01 b$ & $0.13 \pm 0.01 \mathrm{c}$ & $2.74 \pm 0.15 c$ \\
\hline \multirow{2}{*}{ ( $1^{\text {st }}$ crop) } & $\mathrm{T} 1$ & $6.47 \pm 0.82 \mathrm{ab}$ & $4.03 \pm 0.29 \mathrm{ab}$ & $0.28 \pm 0.01 \mathrm{ab}$ & $0.44 \pm 0.07 \mathrm{~b}$ & $11.2 \pm 0.49 b$ \\
\hline & $\mathrm{T} 2$ & $7.70 \pm 0.48 \mathrm{a}$ & $5.12 \pm 0.16 \mathrm{a}$ & $0.34 \pm 0.00 \mathrm{a}$ & $0.60 \pm 0.01 \mathrm{a}$ & $13.7 \pm 0.35 \mathrm{a}$ \\
\hline Maturity & $\mathrm{Ck}$ & $2.16 \pm 0.21 b$ & $1.58 \pm 0.20 \mathrm{ab}$ & $0.36 \pm 0.06 \mathrm{c}$ & $0.47 \pm 0.03 \mathrm{c}$ & $4.57 \pm 0.22 \mathrm{c}$ \\
\hline \multirow[t]{2}{*}{ ( $1^{\text {st }}$ crop) } & $\mathrm{T} 1$ & $3.75 \pm 0.30 \mathrm{a}$ & $2.28 \pm 0.13 \mathrm{a}$ & $1.30 \pm 0.21 \mathrm{a}$ & $1.54 \pm 0.16 \mathrm{a}$ & $8.87 \pm 0.34 \mathrm{a}$ \\
\hline & $\mathrm{T} 2$ & $3.01 \pm 0.21 \mathrm{ab}$ & $1.84 \pm 0.06 \mathrm{ab}$ & $0.94 \pm 0.07 \mathrm{ab}$ & $1.26 \pm 0.1 \mathrm{ab}$ & $7.06 \pm 0.08 b$ \\
\hline Tillering & $\mathrm{Ck}$ & $0.43 \pm 0.07 \mathrm{c}$ & $0.34 \pm 0.03 b$ & $0.00 \pm 0.00 \mathrm{ab}$ & $0.04 \pm 0.00 \mathrm{a}$ & $0.80 \pm 0.05 \mathrm{c}$ \\
\hline \multirow[t]{2}{*}{ ( $2^{\text {nd }}$ crop) } & $\mathrm{T} 1$ & $1.33 \pm 0.30 \mathrm{~b}$ & $0.55 \pm 0.01 \mathrm{a}$ & $0.03 \pm 0.00 \mathrm{a}$ & $0.04 \pm 0.00 \mathrm{a}$ & $1.94 \pm 0.30 \mathrm{~b}$ \\
\hline & $\mathrm{T} 2$ & $2.45 \pm 0.13 \mathrm{a}$ & $0.64 \pm 0.08 \mathrm{a}$ & $0.02 \pm 0.00 \mathrm{ab}$ & $0.07 \pm 0.00 \mathrm{a}$ & $3.17 \pm 0.06 \mathrm{a}$ \\
\hline & $\mathrm{Ck}$ & $0.56 \pm 0.13 \mathrm{ab}$ & $7.03 \pm 0.78 \mathrm{c}$ & $0.03 \pm 0.00 \mathrm{~b}$ & $0.06 \pm 0.00 \mathrm{~b}$ & $7.68 \pm 0.81 \mathrm{c}$ \\
\hline \multirow[t]{2}{*}{ ( $2^{\text {nd }}$ crop) } & $\mathrm{T} 1$ & $0.88 \pm 0.19 \mathrm{a}$ & $18.21 \pm 1.77 \mathrm{a}$ & $0.08 \pm 0.02 \mathrm{a}$ & $0.23 \pm 0.03 \mathrm{a}$ & $19.3 \pm 1.84 \mathrm{a}$ \\
\hline & $\mathrm{T} 2$ & $0.57 \pm 0.03 \mathrm{ab}$ & $12.58 \pm 1.02 b$ & $0.05 \pm 0.02 \mathrm{ab}$ & $0.24 \pm 0.05 \mathrm{a}$ & $13.4 \pm 0.93 b$ \\
\hline & $\mathrm{Ck}$ & $0.57 \pm 0.22 \mathrm{a}$ & $8.78 \pm 0.55 b$ & $0.03 \pm 0.00 \mathrm{a}$ & $0.08 \pm 0.02 \mathrm{ab}$ & $9.46 \pm 0.60 \mathrm{~b}$ \\
\hline \multirow[t]{2}{*}{ ( $\left.2^{\text {nd }} \mathrm{crop}\right)$} & $\mathrm{T} 1$ & $0.67 \pm 0.06 \mathrm{a}$ & $20.46 \pm 2.65 a$ & $0.05 \pm 0.02 \mathrm{a}$ & $0.23 \pm 0.06 \mathrm{a}$ & $21.4 \pm 2.78 \mathrm{a}$ \\
\hline & $\mathrm{T} 2$ & $0.91 \pm 0.37 \mathrm{a}$ & $10.75 \pm 2.19 b$ & $0.03 \pm 0.00 \mathrm{a}$ & $0.18 \pm 0.00 \mathrm{a}$ & $11.8 \pm 2.52 b$ \\
\hline
\end{tabular}

All values are presented as mean \pm standard error $(n=3)$ and means with different letters in the same column for each of the five sampling occasions are significantly different $(p<0.05)$. 
Table 5 Concentration $(\mathrm{mg} / \mathrm{kg}$ ) of various As species in the leaf portion of the rice plant during different growth stages for the pot experiment

\begin{tabular}{lcllllc}
\hline Growth stage & Treatment & Arsenate-As & Arsenite-As & MMA-As & DMA-As & Sum \\
\hline Heading & Ck & $1.64 \pm 0.16 \mathrm{~b}$ & $1.76 \pm 0.22 \mathrm{c}$ & $0.08 \pm 0.01 \mathrm{a}$ & $0.06 \pm 0.01 \mathrm{~b}$ & $3.53 \pm 0.33 \mathrm{~b}$ \\
$\left(1^{\text {st }}\right.$ crop) & T1 & $5.16 \pm 0.36 \mathrm{a}$ & $3.48 \pm 0.56 \mathrm{ab}$ & $0.09 \pm 0.01 \mathrm{a}$ & $0.23 \pm 0.03 \mathrm{~b}$ & $8.97 \pm 0.87 \mathrm{a}$ \\
& $\mathrm{T} 2$ & $4.45 \pm 0.38 \mathrm{a}$ & $3.83 \pm 0.33 \mathrm{a}$ & $0.11 \pm 0.02 \mathrm{a}$ & $0.88 \pm 0.07 \mathrm{a}$ & $9.27 \pm 0.36 \mathrm{a}$ \\
Maturity & Ck & $1.87 \pm 0.18 \mathrm{c}$ & $1.66 \pm 0.07 \mathrm{c}$ & $0.09 \pm 0.02 \mathrm{a}$ & $0.15 \pm 0.01 \mathrm{~b}$ & $3.77 \pm 0.13 \mathrm{~b}$ \\
$\left(1^{\text {st }}\right.$ crop) & T1 & $4.10 \pm 0.29 \mathrm{a}$ & $4.81 \pm 0.42 \mathrm{ab}$ & $0.08 \pm 0.01 \mathrm{a}$ & $0.28 \pm 0.01 \mathrm{a}$ & $9.27 \pm 0.66 \mathrm{a}$ \\
& T2 & $2.94 \pm 0.31 \mathrm{~b}$ & $5.40 \pm 0.42 \mathrm{a}$ & $0.12 \pm 0.02 \mathrm{a}$ & $0.12 \pm 0.02 \mathrm{~b}$ & $8.58 \pm 0.64 \mathrm{a}$ \\
Tillering & Ck & $1.70 \pm 0.07 \mathrm{c}$ & $2.40 \pm 0.20 \mathrm{ab}$ & $0.04 \pm 0.00 \mathrm{a}$ & $0.06 \pm 0.00 \mathrm{ab}$ & $4.19 \pm 0.18 \mathrm{~b}$ \\
$\left(2^{\text {nd }}\right.$ crop) & T1 & $3.73 \pm 0.28 \mathrm{~b}$ & $4.47 \pm 0.81 \mathrm{a}$ & $0.05 \pm 0.00 \mathrm{a}$ & $0.15 \pm 0.01 \mathrm{a}$ & $8.41 \pm 1.08 \mathrm{a}$ \\
& T2 & $5.57 \pm 0.50 \mathrm{a}$ & $3.04 \pm 0.57 \mathrm{a}$ & $0.05 \pm 0.01 \mathrm{a}$ & $0.09 \pm 0.01 \mathrm{a}$ & $8.76 \pm 1.03 \mathrm{a}$ \\
Heading & Ck & $0.11 \pm 0.01 \mathrm{~b}$ & $1.14 \pm 0.06 \mathrm{~b}$ & $0.00 \pm 0.00 \mathrm{~b}$ & $0.02 \pm 0.00 \mathrm{~b}$ & $1.26 \pm 0.07 \mathrm{~b}$ \\
$\left(2^{\text {nd }}\right.$ crop) & T1 & $0.15 \pm 0.01 \mathrm{ab}$ & $1.88 \pm 0.18 \mathrm{a}$ & $0.02 \pm 0.00 \mathrm{a}$ & $0.05 \pm 0.01 \mathrm{a}$ & $2.10 \pm 0.19 \mathrm{a}$ \\
& T2 & $0.19 \pm 0.02 \mathrm{a}$ & $2.08 \pm 0.21 \mathrm{a}$ & $0.01 \pm 0.00 \mathrm{ab}$ & $0.04 \pm 0.01 \mathrm{ab}$ & $2.32 \pm 0.21 \mathrm{a}$ \\
Maturity & Ck & $1.13 \pm 0.25 \mathrm{a}$ & $7.20 \pm 0.85 \mathrm{ab}$ & $0.14 \pm 0.03 \mathrm{ab}$ & $0.25 \pm 0.04 \mathrm{~b}$ & $8.72 \pm 1.10 \mathrm{a}$ \\
$\left(2^{\text {nd }}\right.$ crop) & T1 & $2.22 \pm 1.14 \mathrm{a}$ & $8.65 \pm 1.00 \mathrm{a}$ & $0.27 \pm 0.03 \mathrm{a}$ & $0.82 \pm 0.09 \mathrm{a}$ & $11.9 \pm 0.45 \mathrm{a}$ \\
& T2 & $2.22 \pm 0.49 \mathrm{a}$ & $7.97 \pm 0.51 \mathrm{a}$ & $0.15 \pm 0.02 \mathrm{ab}$ & $0.80 \pm 0.05 \mathrm{a}$ & $11.1 \pm 1.00 \mathrm{a}$ \\
\hline
\end{tabular}

All values are presented as mean \pm standard error $(n=3)$ and means with different letters in the same column for each of the five sampling occasions are significantly different $(p<0.05)$. 
Table 6 Concentration of total iron and arsenic in the iron plaque of root surface during different growth stages for the pot experiment

\begin{tabular}{llcc}
\hline Growth stage & Treatments & Total Fe $(\mathrm{g} / \mathrm{kg})$ & Total As $(\mathrm{mg} / \mathrm{kg})$ \\
\hline Heading & $\mathrm{Ck}$ & $1.61 \pm 0.10 \mathrm{c}$ & $19.1 \pm 4.84 \mathrm{c}$ \\
$\left(1^{\text {st }}\right.$ crop) & $\mathrm{T} 1$ & $2.34 \pm 0.15 \mathrm{bc}$ & $29.7 \pm 4.19 \mathrm{~b}$ \\
& $\mathrm{~T} 2$ & $21.35 \pm 1.44 \mathrm{a}$ & $55.4 \pm 12.0 \mathrm{a}$ \\
Maturity & $\mathrm{Ck}$ & $15.00 \pm 0.60 \mathrm{a}$ & $73.7 \pm 18.5 \mathrm{c}$ \\
$\left(1^{\text {st }}\right.$ crop) & $\mathrm{T} 1$ & $11.30 \pm 0.36 \mathrm{~b}$ & $330 \pm 20.5 \mathrm{~b}$ \\
& $\mathrm{~T} 2$ & $15.50 \pm 0.49 \mathrm{a}$ & $711 \pm 37.1 \mathrm{a}$ \\
Tillering & $\mathrm{Ck}$ & $17.79 \pm 0.51 \mathrm{a}$ & $235 \pm 3.35 \mathrm{c}$ \\
$2^{\text {nd }}$ crop) & $\mathrm{T} 1$ & $9.79 \pm 0.57 \mathrm{~b}$ & $526 \pm 20.6 \mathrm{~b}$ \\
& $\mathrm{~T} 2$ & $19.43 \pm 1.32 \mathrm{a}$ & $980 \pm 38.2 \mathrm{a}$ \\
Heading & $\mathrm{Ck}$ & $28.28 \pm 3.73 \mathrm{a}$ & $175 \pm 8.86 \mathrm{c}$ \\
$\left(2^{\text {nd }}\right.$ crop) & $\mathrm{T} 1$ & $16.42 \pm 0.57 \mathrm{~b}$ & $562 \pm 13.5 \mathrm{~b}$ \\
& $\mathrm{~T} 2$ & $25.62 \pm 1.10 \mathrm{a}$ & $707 \pm 38.8 \mathrm{a}$ \\
Maturity & $\mathrm{Ck}$ & $17.52 \pm 0.98 \mathrm{ab}$ & $173 \pm 4.98 \mathrm{c}$ \\
$2^{\text {nd }}$ crop) & $\mathrm{T} 1$ & $15.57 \pm 0.43 \mathrm{~b}$ & $297 \pm 3.28 \mathrm{~b}$ \\
& $\mathrm{~T} 2$ & $20.07 \pm 1.17 \mathrm{a}$ & $579 \pm 15.6 \mathrm{a}$ \\
\hline
\end{tabular}

All values are presented as mean \pm standard error $(n=3)$ and means with different letters in the same column for each of the five sampling occasions are significantly different $(p<0.05)$. 
Table 7 The ratios of stem-borne As to root-borne $A s\left(\mathrm{As}_{S t e m} / \mathrm{As}_{\mathrm{Root}}\right)$ in the different growth stages of rice plants for the control and the treatments for the pot experiment

\begin{tabular}{llccccc}
\hline Growth stage & Treatment & Arsenate-As & Arsenite-As & MMA-As & DMA-As & Sum \\
\hline Heading (1 ${ }^{\text {st }}$ crop) & Ck & 0.110 & 0.053 & 0.158 & 1.300 & 0.083 \\
& T1 & 0.088 & 0.067 & 0.231 & 0.312 & 0.082 \\
& T2 & 0.651 & 0.156 & 0.523 & 0.759 & 0.298 \\
Mature (1 ${ }^{\text {st }}$ crop) & Ck & 1.785 & 0.224 & 0.456 & 0.528 & 0.460 \\
& T1 & 1.847 & 0.076 & 1.092 & 2.567 & 0.262 \\
Tillering (2nd crop) & T2 & 0.788 & 0.083 & 0.618 & 0.984 & 0.245 \\
& Ck & 0.050 & 0.030 & 0.000 & 0.068 & 0.039 \\
& T1 & 0.016 & 0.006 & 0.010 & 0.016 & 0.011 \\
Heading (2nd crop) & T2 & 0.088 & 0.035 & 0.118 & 0.106 & 0.068 \\
& T1 & 0.184 & 0.481 & 0.214 & 0.045 & 0.401 \\
& T2 & 0.179 & 0.366 & 0.229 & 0.299 & 0.348 \\
Mature (2 ${ }^{\text {nd }}$ crop) & Ck & 0.087 & 0.240 & 0.227 & 0.189 & 0.223 \\
& T1 & 0.356 & 1.777 & 0.088 & 0.160 & 1.282 \\
& T2 & 0.354 & 2.200 & 0.035 & 0.315 & 1.606 \\
& & 0.565 & 0.866 & 0.037 & 0.205 & 0.753 \\
\hline
\end{tabular}


Table 8 The ratios of leaf-borne As to root-borne $A s\left(A s_{\text {leaf }} / A s_{\text {Root }}\right)$ in the different growth stages of rice plants for the control and the treatments for the pot experiment

\begin{tabular}{lcccccc}
\hline Growth stage & Treatment & Arsenate-As & Arsenite-As & MMA-As & DMA-As & Total \\
\hline Heading $\left(1^{\text {st }}\right.$ crop) & Ck & 0.128 & 0.092 & 0.067 & 0.600 & 0.106 \\
& T1 & 0.070 & 0.058 & 0.074 & 0.163 & 0.066 \\
Mature ( $1^{\text {st }}$ crop) & T2 & 0.376 & 0.116 & 0.169 & 1.114 & 0.201 \\
& Ck & 1.545 & 0.236 & 0.114 & 0.169 & 0.380 \\
& T1 & 2.020 & 0.160 & 0.067 & 0.467 & 0.274 \\
Tillering (2 & T2 & 0.770 & 0.244 & 0.079 & 0.094 & 0.298 \\
& Ck & 0.199 & 0.215 & 1.333 & 0.102 & 0.206 \\
Heading $\left(2^{\text {nd }}\right.$ crop) & T1 & 0.045 & 0.052 & 0.017 & 0.060 & 0.048 \\
& T2 & 0.200 & 0.166 & 0.294 & 0.136 & 0.187 \\
& Ck & 0.036 & 0.078 & 0.000 & 0.015 & 0.066 \\
Mature $\left(2^{\text {nd }}\right.$ crop) & T1 & 0.031 & 0.038 & 0.057 & 0.065 & 0.038 \\
& T2 & 0.029 & 0.040 & 0.045 & 0.031 & 0.038 \\
& Ck & 0.706 & 1.457 & 0.412 & 0.500 & 1.182 \\
& T1 & 1.175 & 0.930 & 0.190 & 1.123 & 0.896 \\
& T2 & 1.379 & 0.642 & 0.183 & 0.909 & 0.708 \\
\hline
\end{tabular}




\section{Supplementary Material}

Supplementary Table S1 Instrumental operating conditions for the HPLC-ICP-MS system

\begin{tabular}{ll}
\hline Parameter & Detailed information \\
\hline HPLC & Agilent 1260 \\
Column & Athena C18-WP column $(4.6 * 250 \mathrm{~mm}, 5 \mu \mathrm{m}, \mathrm{CNW})$ \\
& $\mathrm{CNW}$ guard column (Athena C18-WP, $\left.4.0^{*} 20 \mathrm{~mm}, 5 \mu \mathrm{m}\right)$ \\
Mobile phase & $2.5 \mathrm{mM}$ Citric acid/2.5 mM Sodium sulfonate $(\mathrm{pH} 4.5)$ \\
Flow rate & $1.0 \mathrm{~mL} / \mathrm{min}$ \\
Injected volume & $20 \mu \mathrm{L}$ \\
ICP-MS & Agilent 7700 \\
RF (forward and reflected power) & $1550 \mathrm{~W}$ \\
Spray chamber & Quartz dual channel type \\
Carrier gas & $0.75 \mathrm{~L} / \mathrm{min}$ \\
Make-up gas & $0.40 \mathrm{~L} / \mathrm{min}$ \\
Sample introduction & Meinhard nebulizer \\
Channels monitored & 75,77 and 78 \\
\hline
\end{tabular}

